\title{
Modelling the damage costs of invasive alien species
}

\author{
Danish A. Ahmed (D) Emma J. Hudgins $($ D - Ross N. Cuthbert $($ D \\ Phillip J. Haubrock (D) David Renault (D) Elsa Bonnaud $(\mathbb{D} \cdot$ Christophe Diagne $(\mathbb{D} \cdot$ \\ Franck Courchamp $\mathbb{D}$
}

Received: 11 November 2020/ Accepted: 14 June 2021/Published online: 28 July 2021

(C) The Author(s) 2021

\begin{abstract}
The rate of biological invasions is growing unprecedentedly, threatening ecological and socioeconomic systems worldwide. Quantitative understandings of invasion temporal trajectories are essential to discern current and future economic impacts of invaders, and then to inform future management strategies. Here, we examine the temporal trends of
\end{abstract}

D. A. Ahmed ( $\bowtie)$

Department of Mathematics and Natural Sciences, Centre for Applied Mathematics and Bioinformatics, Gulf

University for Science and Technology, 32093 Hawally,

Kuwait

e-mail: Ahmed.D@gust.edu.kw

\section{E. J. Hudgins}

Department of Biology, McGill University, Montréal,

QC H3A 1B1, Canada

R. N. Cuthbert

GEOMAR Helmholtz-Zentrum Für Ozeanforschung Kiel,

24105 Kiel, Germany

P. J. Haubrock

Department of River Ecology and Conservation,

Senckenberg Research Institute and Natural History

Museum Frankfut, Gelnhausen, Germany

P. J. Haubrock

Faculty of Fisheries and Protection of Waters, South

Bohemian Research Center of Aquaculture and

Biodiversity of Hydrocenoses, University of South

Bohemia in České Budějovice, Zátiší 728/II,

38925 Vodňany, Czech Republic cumulative invasion costs by developing and testing a novel mathematical model with a population dynamical approach based on logistic growth. This model characterises temporal cost developments into four curve types (I-IV), each with distinct mathematical and qualitative properties, allowing for the parameterization of maximum cumulative costs, carrying

\author{
D. Renault \\ Univ Rennes, CNRS, ECOBIO (Ecosystèmes, \\ biodiversité, évolution), UMR 6553, 35000 Rennes, \\ France \\ D. Renault \\ Institut Universitaire de France, 1 Rue Descartes, \\ 75231 Paris cedex 05, France \\ E. Bonnaud - C. Diagne - F. Courchamp \\ Université Paris-Saclay, CNRS, AgroParisTech, Ecologie \\ Systématique Evolution, 91405 Orsay, France
}


capacities and growth rates. We test our model using damage cost data for eight genera (Rattus, Aedes, Canis, Oryctolagus, Sturnus, Ceratitis, Sus and Lymantria) extracted from the InvaCost databasewhich is the most up-to-date and comprehensive global compilation of economic cost estimates associated with invasive alien species. We find fundamental differences in the temporal dynamics of damage costs among genera, indicating they depend on invasion duration, species ecology and impacted sectors of economic activity. The fitted cost curves indicate a lack of broadscale support for saturation between invader density and impact, including for Canis, Oryctolagus and Lymantria, whereby costs continue to increase with no sign of saturation. For other taxa, predicted saturations may arise from data availability issues resulting from an underreporting of costs in many invaded regions. Overall, this population dynamical approach can produce cost trajectories for additional existing and emerging species, and can estimate the ecological parameters governing the linkage between population dynamics and cost dynamics.

Keywords Biological invasions - Cost modelling · InvaCost $\cdot$ Logistic growth · Non-native species ·

Population dynamics $\cdot$ Resource damages .

Socioeconomic impacts

\section{Introduction}

The introduction, establishment and spread of invasive alien species (IAS) continues to erode biodiversity across biogeographic regions (Simberloff et al. 2013; Bellard et al. 2016). Global translocations of IAS are accelerating (Seebens et al. 2017, 2021), owing to globalisation-mediated intensification of trade and transport networks that increasingly interconnect novel species pools across historically separated areas (Seebens et al. 2018). The process of biological invasion is characterised by several discrete stages: transport, introduction, establishment and spread, with invasion success being impeded by geographical, biological and/or ecological features at each stage (Blackburn et al. 2011).

By reducing or extirpating native populations (Bellard et al. 2016; Vanbergen et al. 2018), IAS considerably affect biotic and abiotic interactions of recipient communities, with frequent top-down or bottom-up cascading effects (Walsh et al. 2016; Bucciarelli et al. 2018). As such, IAS can compromise ecosystem structure, function and service provisioning (Malcolm and Markham 2000; Stigall 2010; Vanbergen et al. 2018; Blackburn et al. 2019). Moreover, multiple IAS can interact mutualistically (Crane et al. 2020), and can cause a considerable effect on human health through, for example, the vectoring of pathogens and parasites that cause disease (Juliano and Lounibos 2005), or the diffusion of pollen-induced allergies (Schaffner et al. 2020). In turn, the abovementioned ecological and health impacts of IAS can translate into the accrual of marked economic costs to a diversity of activity sectors (Bradshaw et al. 2016).

Despite the huge threat of IAS to biodiversity, human health and national economies, the capacity to prevent and manage invasions has remained poorly developed in many countries (Early et al. 2016). The limited international coordination for establishing management measures is even more striking. In particular, management has long been given low priority, most probably because it was assumed that such costs would be high relative to the potential benefits they could confer (Heikkilä 2011). However, management investments at early invasion stages, such as biosecurity, can prove more cost-effective than long-term control (Leung et al. 2002). Nonetheless, a variety of mitigation actions are conducted in managed areas worldwide (Veitch and Clout 2002; Rumlerová et al. 2016), but only limited information on IAS-associated costs exists under specific regional, taxonomic, or activity sector contexts, as well as over temporal scales. As a result, hitherto, the few largescale studies of invasion costs have merely represented monetary totals (e.g., Pimentel et al. 2000, 2005) without accounting for the temporal dynamics or the complex typology of costs (e.g., management and damages). Therefore, so far it has not been possible to decipher how invasion costs are evolving over time, as well as how these trajectories might differ among taxonomic groups or invaded habitats. Yet, the impacts of IAS are not necessarily constant across a spatiotemporal context, and are likely to evolve when IAS populations grow and/or expand (Parker et al. 1999; Dickey et al. 2020), or because of lags in species detection that govern the deployment of control measures. For economic damages in particular, the extent to which costs track 
population dynamics remains poorly understood, while such information on cost dynamics is crucial to design, prioritize and adapt management actions (Diagne et al. 2020a). Indeed, studies highlighting IAS economic cost trajectories could help divert more funds to biosecurity and other management actions, or set IAS management priorities to mitigate further damages. Especially, identifications of IAS for which damage costs are yet to saturate, versus those that have plateaued with time, could inform more efficient management measures among species.

Much of the current literature on the relationship between the cost of invasions and time comes from optimal IAS control theory (Hastings et al. 2007; Bogich et al. 2008; Epanchin-Niell 2017; Baker et al. 2019). In these studies, the costs under consideration mainly correspond to control efforts, and are tied closely to abundance, with increased control typically diminishing management benefits when IAS abundance becomes small and specimens more difficult to detect. Given that most models have focused on control costs, quantitative understandings of how damage costs relate to invader population dynamics are urgently required. These quantifications will improve the reliability of cost models and extend their scope, where the examination of IAS costs can instead be based on the impacts directly related to damage. Indeed, the exclusion of costs related to preventative measures, surveillance and management, among others (Robertson et al. 2020), which are subject to investment decisions that can differ spatiotemporally irrespective of impact, allows us to assume that the impacts of IAS are synonymous to their damage costs.

Parker et al. (1999) presented a basic framework for understanding how species abundance, severity of damage, and the size of their invaded range relate to their total impact. In its original formulation, the authors assumed a constant per capita impact over time for a pest with a given range size, where impact is related only to abundance and species spread. However, the empirical support for this model is equivocal, as there are likely many scenarios where per capita costs are not constant over time. Damages can vary from one year to the next, and this variance can depend on the taxonomic and trophic groups considered (Lehmann et al. 2020). In particular, differential per capita IAS impacts at different population densities can substantially modulate the extent of the ecological impacts of a given IAS population from one year to the next. Also, the trophic requirements and climate sensitivity of the IAS, in particular for insects, may greatly change along their ontogeny (Stockhoff 1993). Finally, a variety of synergies (Beggel et al. 2016; Zenni et al. 2020) and lags (Aikio et al. 2010; Coutts et al. 2017) may complicate the temporal trend of per capita IAS costs, and have so far lacked consideration.

To provide an urgently needed basis for the quantification of IAS-induced costs, the InvaCost database has recently been developed (Diagne et al. 2020b). This database contains extensive information on the costs (e.g., type of costs, impacted sectors, geographic attributes, reliability of cost estimations, etc.) associated with approximately 340 IAS. In this study, we use this cost information by presenting a dynamical approach to modelling the accumulated damage costs of various IAS with the most resolute records in InvaCost. Global accumulated costs are obtained by summing all reported costs across species and countries within a given year for each genus over time. In doing so, we asked whether the temporal cumulation of costs showed generalities among taxa, or if types of relationships varied given differences in life history traits. Further, we used the model to quantify and compare both cost (maximum cumulated cost) and population (intrinsic growth rate) parameters among the taxa. We addressed this question using the cost-density function proposed by Yokomizo et al. (2009), which presents four possible relationships with distinct properties at different density levels (low threshold, S-shaped, linear and high threshold curves), that relate the cost of impact to population density. We tested the application of our temporal cost model against data extracted from the InvaCost database for eight well-represented genera of interest that spanned a range of damaging invasive animal species: Rattus (rats), Aedes (mosquitoes), Canis (dogs), Oryctolagus (rabbits), Sturnus (starlings), Ceratitis (fruit flies), Sus (pigs) and Lymantria (moths). This test set allowed the examination of both the differential prioritization of allocated costs and the temporal cost patterns across taxonomic groupings with various life history traits. 


\section{Methods}

Density-time function based on logistic growth

The temporal population dynamics of a single species can be described by the generic differential equation:

$u^{\prime}(t)=u f(u)$

where $u=u(t)$ is the time-dependent population density, $u^{\prime}(t)$ is the rate of change in density with respect to time, and $f(u)$ is the per capita growth rate. For many populations (including IAS), the growth is bounded, a consequence of the fact that resources are usually limited (e.g., food, habitat etc.). Under such a scenario, the density levels off in the long term, imposing a saturation level known as the carrying capacity $K$. At a simple level, the corresponding dynamics can be modelled using the logistic equation (Jensen 1975; Lewis et al. 2016), which reads:

$u^{\prime}(t)=\alpha u\left(1-\frac{u}{K}\right)$

where $\alpha$ is the intrinsic growth rate. This equation can be readily solved to obtain:

$u(t)=\frac{K}{1+\left(\frac{K}{u_{0}}-1\right) \exp (-\alpha t)}$ given that the value of the initial density $u_{0}=u(0)$ is prescribed (Petrovskii and Li 2006; Lewis et al. 2016).

Figure 1 Plot (a) shows that there are two steady states found at $u=0$ (unstable) and $u=K$ (stable), and the maximum growth rate occurs at half the carrying capacity $K / 2$ with value $\alpha K / 4$. Plot (b) illustrates solution curves to the logistic equation (3), whose dynamics depend on whether the initial density $u_{0}$ is less than or greater than $K$. For very low densities $u \ll K$ and on a short time-scale, the density grows exponentially $u \approx u_{0} e^{\alpha t}$, due to local aggregation. For longer times, the density grows much more slowly and exhibits near exponential decay to the carrying capacity due to the negative feedback from intraspecific competition. In the case that $u>K$, the population can no longer be sustained, resulting in a gradual decline. In either case, in the large time limit, the density levels off when the carrying capacity $K$ of the environment is approached. In the absence of any population density data, $K$ is only identifiable up to a constant, since $u$ and $K$ can be re-scaled by any constant to produce the same solution. In contrast, the intrinsic growth rate $\alpha$ is fully identifiable. In our cost modelling approach, we set $u_{0}$ equal to 1 , which is assumed to be much less than $K$, as the density of the

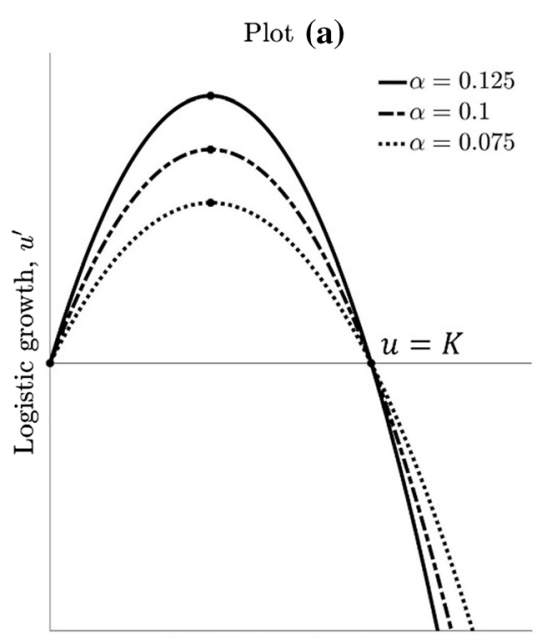

Population density, $u$
Plot (b)

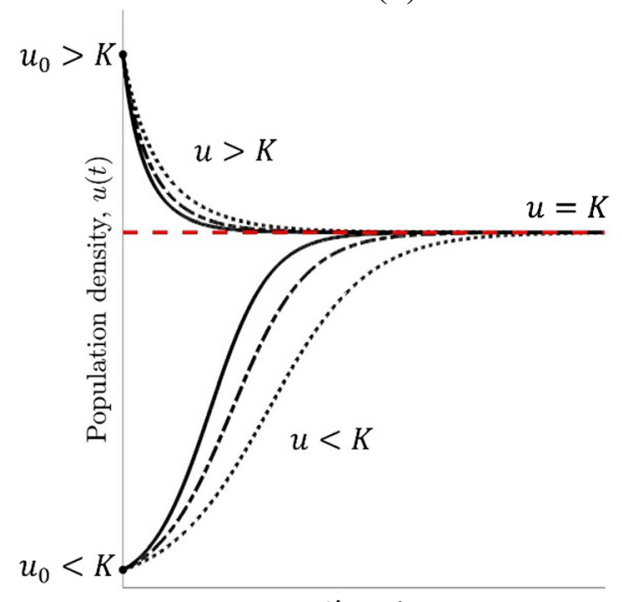

time, $t$

Fig. 1 a Logistic growth given by Eq. (2). b Population density as a function of time given by Eq. (3) 
IAS is usually expected to be relatively low at the time of introduction.

Accumulated cost as a function of IAS population density (cost-density functions)

The relationships between ecological impacts and the population density of an IAS have often been examined (also known as density-impact curves), with both linear and non-linear relationships proposed (NavaCamberos et al. 2001; Finnoff et al. 2005; Laverty et al. 2017; Bradley et al. 2019; Moroń et al. 2019); however, only a few studies have attempted to link this to the damage costs incurred. For a more thorough investigation of the variety of forms of the cost-density function (i.e., the accumulated $\operatorname{cost} C$ as a function of density $u$ ), we chose to rely on the functional types proposed by Yokomizo (2009), written as:

$C(u)=A C_{\max }\left[\frac{1}{\frac{1-B}{B} \exp \left(-\frac{u}{s_{2} K}\right)+1}-B\right]$

with

$$
\begin{array}{r}
A=\frac{1+e^{-s}}{1-B\left(1+e^{-s}\right)}, B=\frac{1}{1+\exp \left(\frac{1}{s_{2}}-s\right)}, \\
s=\frac{1-s_{1}}{s_{2}}
\end{array}
$$

where $C_{\max }$ is the maximum accumulated cost of impact, $K$ is the carrying capacity, $s_{1}, s_{2}$ are the curve shape parameters which lie between 0 and 1 inclusive, and $A, B, s$ are parameters that are expressed in terms of these shape parameters. Note that this model choice is supported by its frequent use by other authors when assessing impacts (see e.g., Jackson et al. 2015; Vander Zanden et al. 2017; Roberts et al. 2018; Sofaer et al. 2018).

Figure 2 illustrates four functional types which express the accumulated cost in terms of IAS population density with distinct behaviours at different density levels.

- For the Type (i) low threshold curve, the accumulated cost increases relatively fast at low IAS population densities, and remains high at intermediate/larger densities.

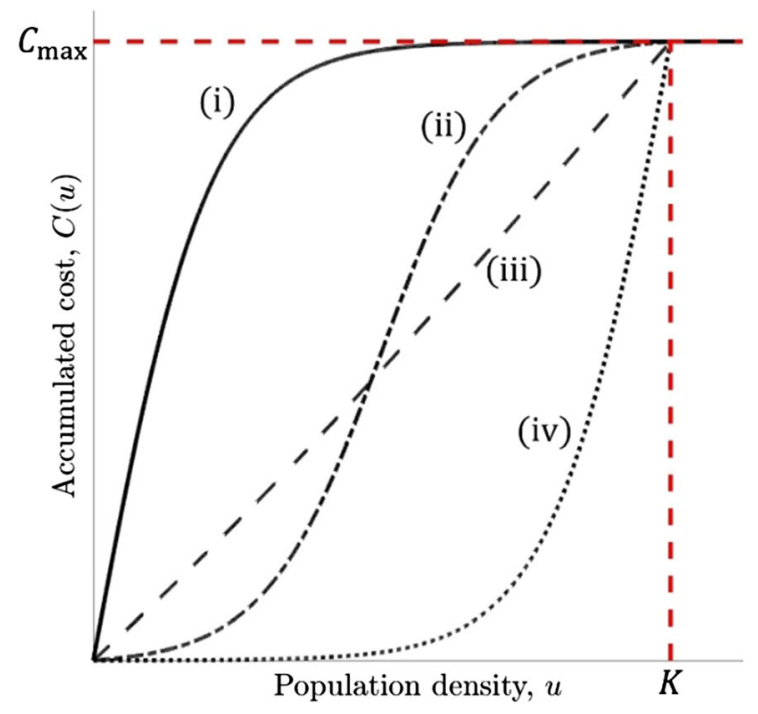

Fig. 2 Illustration of the four types of cost-density functions. Type (i) Low-threshold curve with shape parameters $s_{1}=0, s_{2}=0.1$, Type (ii) S-shaped (sigmoidal) curve $s_{1}=0.5, s_{2}=0.1$, Type (iii) Linear curve $s_{1}=1, s_{2}=1$ and Type (iv) High-threshold curve $s_{1}=1, s_{2}=0.1$

- For the Type (ii) S-shaped curve, the accumulated cost increases much faster at intermediate values of IAS population density in comparison to Type (iii).

- The Type (iii) linear curve presents a directly proportional relationship.

- For the Type (iv) high threshold curve, the accumulated cost remains modest at low IAS population densities, but increases rapidly for larger densities.

In the case $u>K$, one may expect annual costs to remain constant and of a considerable magnitude, in which case the accumulated costs will grow linearly with time. However, for this study, we assume that the threshold density has not been reached, so that $u<K$. Given this, the cost-density function in Eqs. (4)-(5) applies with limiting behaviour $C \rightarrow C_{\max }$ as $u \rightarrow K$. Here, $C_{\max }$ represents a 'localized' maximum accumulated cost as spatial aspects are not accounted for. This provides an adequate description for scenarios where the IAS has stopped spreading (i.e., reached its bioclimatic niche limits) (Barnett 2001; Aplin et al. 2011). Also, in a more realistic scenario, annual damage costs may continue during this phase, but these costs can be expected to be several orders of magnitude smaller than the largest annual cost, and the total cost is likely driven more by management costs, 
which we do not consider. As a result, the increase in the accumulated cost would be negligible, and therefore can be considered at a 'near' saturation level, i.e., with constant $\mathrm{C}_{\max }$.

For all four cost function types, the accumulated cost scales linearly at very low IAS population densities. This is consistent with the concept of invasion debt (Essl et al. 2011). To demonstrate this, consider a species population at low density and relatively large carrying capacity $K$, so that terms of the order $(u / K)^{2}$ and higher are negligible and can be omitted. It follows that one can approximate the accumulated cost as follows:

$C(u) \approx A C_{\max } \cdot \frac{B(1-B)}{s_{2} K} \cdot u$

We note that the model assumes that the accumulated damage cost remains constant over time given a fixed IAS density. This may be reasonable on a short time scale, but in the long-term, the damage cost for a given IAS density may change, e.g., due to economic growth (Haubrock et al. 2021).

In an ecological context, Type (i) costs may be common for species whose impacts are roughly equivalent across all abundance levels, reaching near-maximal accumulated costs at relatively small densities. At the other extreme, Type (iv) costs correspond to species whose damages are only felt once they have reached very high abundance (Yokomizo et al. 2009). As an illustration, fouling species who require high densities in order to block pipes, such as zebra mussels, may be described by Type (iv) (Elliott et al. 2005). Conversely, highly voracious novel predators introduced in insular communities, such as the feral cat (Felis catus) (Hilton and Cuthbert 2010) may rather behave as Type (i). Indeed, these predators have been able to have deleterious impacts on native fauna that begin even at low densities, and that do not appear to saturate until near maximal densities. Alternatively, species could show linear relationships with cost (Type iii) if per capita impacts are density-independent. This form has been found for a well-known agricultural pest, the balsam fir sawfly (Neodiprion abietis, Parsons et al. 2005). Most often, linear relationships have been suggested as being common in nature (see e.g., Elgersma and Ehrenfeld 2011; Panetta and Gooden 2017). Finally, relationships could be sigmoidal (Type ii) if density plays both a positive and negative role, which would be expected if interference limits impacts at high density, while being by definition low at low density. This form is predicted in models of invasive rodent grazing impacts on crops (Brown et al. 2007).

Accumulated cost as a function of elapsed time since the introduction of IAS (cost-time functions)

The accumulated cost-density function can be expressed explicitly in terms of time $C(t)$ by combining Eq. (4) and the density-time function in Eq. (3).

The four accumulated cost functions, which are now time dependent, i.e., cost models (I)-(IV), see Fig. 3, correspond to each density dependent cost functional Types (i)-(iv), see Fig. 2. These models present distinct qualitative properties depending on the time scale, but more generally, the cost patterns at low/high IAS population densities mimic those seen in Fig. 2. Overall, costs increase monotonically until a maximum level $C_{\max }$ is approached, precisely when the IAS density saturates to the carrying capacity. Also, given the accumulated cost as a function of time, crude estimates of the marginal cost can be obtained over some time interval $t_{1}<t<t_{2}$, computed as $C\left(t_{2}\right)-C\left(t_{1}\right)$. In the case of low IAS population densities and on a short time scale, with relatively high carrying capacity, one can obtain from Eq. (6):

$C(t) \approx A C_{\max } \cdot \frac{B(1-B)}{s_{2} K} \cdot u_{0} e^{\alpha t}$,

which demonstrates that all cost models (I)-(IV) allow for a rapid increase in damage costs that arise due to the rapid spread of the IAS shortly after its initial introduction. This is a direct result of the fact that logistic growth in the population assumes that the species density grows exponentially on a short time scale, which is normally the case for successful invaders during the early phases of the invasion (Shigesada 1997; Crooks 2005). Nonetheless, 'invasion debt' can result in considerable lag times between invader arrival and perceived impact (Essl et al. 2011).

Data collection and processing

Cost data were extracted from the InvaCost database (2419 entries; Diagne et al. 2020b, https://doi.org/10. 1038/s41597-020-00586-z) as well as another related data source from searches made in non-English 


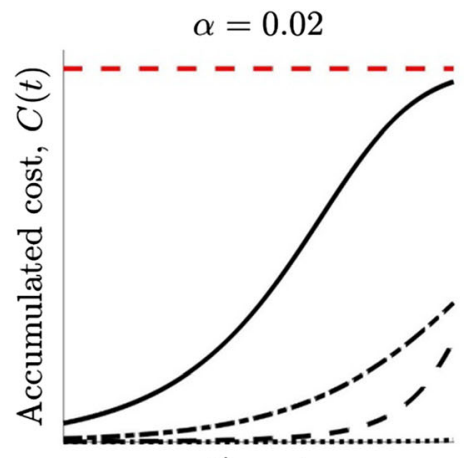

time, $t$

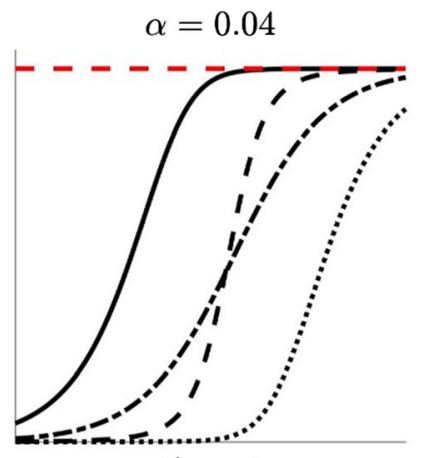

time, $t$

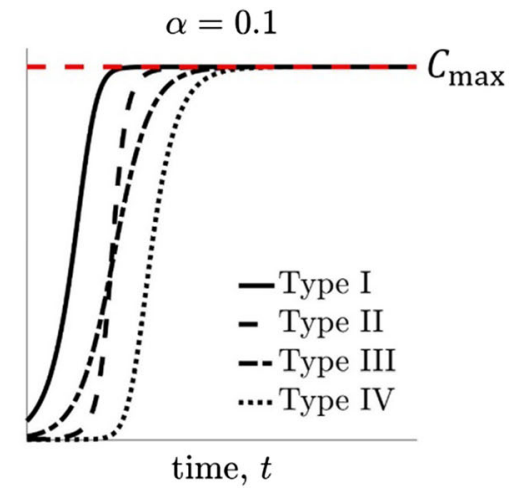

Fig. 3 Accumulated cost models (I)-(IV) over time since the introduction of IAS, corresponding to each functional Type (i)-(iv), respectively (see Fig. 2), presented for different values of intrinsic growth rate $\alpha$. Line styles are the same as in Fig. 2

documents (5212 entries; Angulo et al. 2020; available at https://doi.org/10.6084/m9.figshare.12928136). Literature sources were obtained via systematic searches in online repositories (Web of Science, Google Scholar and Google search engine). We gathered additional cost information through contacting experts and searching specific literature databases of the countries/languages considered, and contacting official national managers or researchers that could provide cost data. All cost entries were standardized to a common currency and year for comparability (2017 US\$). This process also considered an inflation factor based on the Consumer Price Index of 2017 relative to the year of the cost estimation. All information on the compilation and standardization of data recorded in InvaCost are detailed in Diagne et al. (2020b). Also, we provide the Appendix A1 for presenting the categories used for each descriptive variable, which corresponds to a specific column in the InvaCost database (Diagne et al. 2020b).

For analyses implemented in the present study, we extracted entries for all species within the following focal genera: Rattus (rats), Aedes (mosquitoes), Canis (dogs), Oryctolagus (rabbits), Sturnus (starlings), Ceratitis (fruit flies), Sus (pigs) and Lymantria (moths). They were chosen as they comprised some of the richest data, and represented various taxonomic groups and therefore contrasted life history traits, especially concerning invasion dynamics. For these genera, the cost entries selected were those estimated at the country level, i.e., not provided at supra-national or site scales (Table 1; see Appendix A2 for a distribution map of total economic costs (US\$ million) at the country level). For this purpose, we filtered these genera using the "Genus" column, and only incorporated entries at the Country level within the "Spatial_scale" column. We excluded any cost estimates that were considered to have Low reliability (i.e., not sourced from official/peer-reviewed material or not reproducible; "Method_reliability" column), and any costs that were Potential (i.e., predicted or extrapolated), rather than actually Observed ("Implementation" column) based on the database contents at the time of extraction (Diagne et al. 2020b). We note that entries used here may have since been updated in InvaCost v4.0 (for example, Lymantria spp. costs in Mexico are now listed as Potential rather than Observed).

For each entry, we also extracted the timespan associated with the costs recorded using the $e x$ pandYearlyCosts function from the invacost $\mathrm{R}$ package (Leroy et al. 2020). This function divides the total cost reported by a publication equally across a set of probable starting and ending years, and provides an extended dataset where each entry corresponds to a cost estimate occurring for a single year. Each publication within the InvaCost database acted as an independent reference on reported costs, but the number of years over which the cost was estimated varied across references. Only those genera possessing cost estimates from at least five independent references were considered from the InvaCost database (Table 1).

All reported costs were summed across species and countries within a given year to obtain a global accumulated cost for each genus over time (see also Appendix A2). Table 1 shows the number of independent references used to produce each genus' cost 
Table 1 A list of the eight genera used to create cost curves. The years in which extreme costs (outliers) occurred, and the corresponding cost values are given for each genus, where a blank space indicates that no outliers were found. The number of independent references indicates how many separate publications within the InvaCost database were used to create the cost curve for that genus, while the number of independent years is the unique cost-year combination for each genus after all independent references were aggregated

\begin{tabular}{llllll}
\hline Genus & $\begin{array}{l}\text { Time } \\
\text { period }\end{array}$ & Outlier & & $\begin{array}{l}\text { No. of } \\
\text { independent } \\
\text { references }\end{array}$ & $\begin{array}{l}\text { No. of independent } \\
\text { years associated } \\
\text { with costs }\end{array}$ \\
\cline { 2 - 3 } & Year(s) & $\begin{array}{l}\text { Outlier cost } \\
\text { US\$ million }\end{array}$ & & \\
\hline
\end{tabular}

\begin{tabular}{ll}
\hline (a) Rattus & $1998-2010$ \\
(b) Aedes & $1977-2017$ \\
(c) Canis & $1979-2014$ \\
(d) Oryctolagus & $1955-2019$
\end{tabular}

\begin{tabular}{|c|c|}
\hline (e) Sturnus & 2000-2016 \\
\hline (f) Ceratitis & 1999-2007 \\
\hline (g) Sus & 1982-2016 \\
\hline (h) Lymantria & 1933-2020 \\
\hline
\end{tabular}

$\begin{array}{lr}1953 & 432.01 \\ 1996 & 733.77 \\ 2001 & 1938.07 \\ 2003 & 518.50 \\ 2010 & 433.09\end{array}$

1981

2017

1981

2002

2004

$\begin{array}{rr}6 & 6 \\ 34 & 25 \\ 7 & 6 \\ 16 & 31\end{array}$

6

25

31

733.77

18.50

6

$\begin{array}{lll}13.50 & 5 & 5\end{array}$

$\begin{array}{lll}2293.53 & 10 & 9\end{array}$

$\begin{array}{lll}3355.99 & 8 & 39\end{array}$

2203.89

368.50 curve, as well as the number of unique years for which a total cost could be calculated (i.e., the number of non-repeated years for which cost data were available from InvaCost across all references). We excluded those cost values from the dataset that reported comparatively very high costs, i.e., any cost value that was greater than $Q_{3}+1.5 \times I Q R$ was removed (see Table 1), where $Q_{3}$ is the upper quartile and $I Q R$ is the interquartile range of the dataset. A single outlier was found for the genera Ceratitis and Sus, while three and five outliers were found for Lymantria and Oryctolagus, respectively. We found no outliers for the other considered genera.

We modelled the accumulated cost data (US\$ million) using the four different types of accumulated cost models (I)-(IV). The first reported year of damage cost was taken as the initial year, corresponding to time $t=0$, which is measured in years thereafter. For example, the time period for Rattus is from 1998 $(t=0)$ to $2010(t=12)$. The non-linear regression curve fitting tool 'fitnlm' from Matlab was used to identify which model optimally fitted the data, and selected it based on the highest coefficient of determination $\left(r^{2}\right)$ or lowest root mean square error
(RMSE). Once the best fitting model was found, we reported the corresponding model parameters for each genus; specifically, the maximum accumulated cost $C_{\text {max }}$, carrying capacity $K$ and the intrinsic growth rate $\alpha$.

\section{Results}

We found fundamental differences among taxa in the nature of their cost accumulations over time, reflected in different best-fitting model types (Fig. 4). Of the eight genera assessed, Rattus was best described by model Type I, Canis by model Type II, Oryctolagus, Sturnus and Ceratitis by model Type III, and lastly Aedes, Sus, and Lymantria by model Type IV (Table 2, Fig. 4). Models for each taxon were associated with a very high $r^{2}(\geq 0.952)$, indicating an extremely close model fit with the cost data, with the exception of Sturnus and Canis, with still high $r^{2}$ values (Table 2). The shaded areas in Fig. 4 represent confidence regions providing the range of predicted cumulative costs. Note that lower confidence levels 

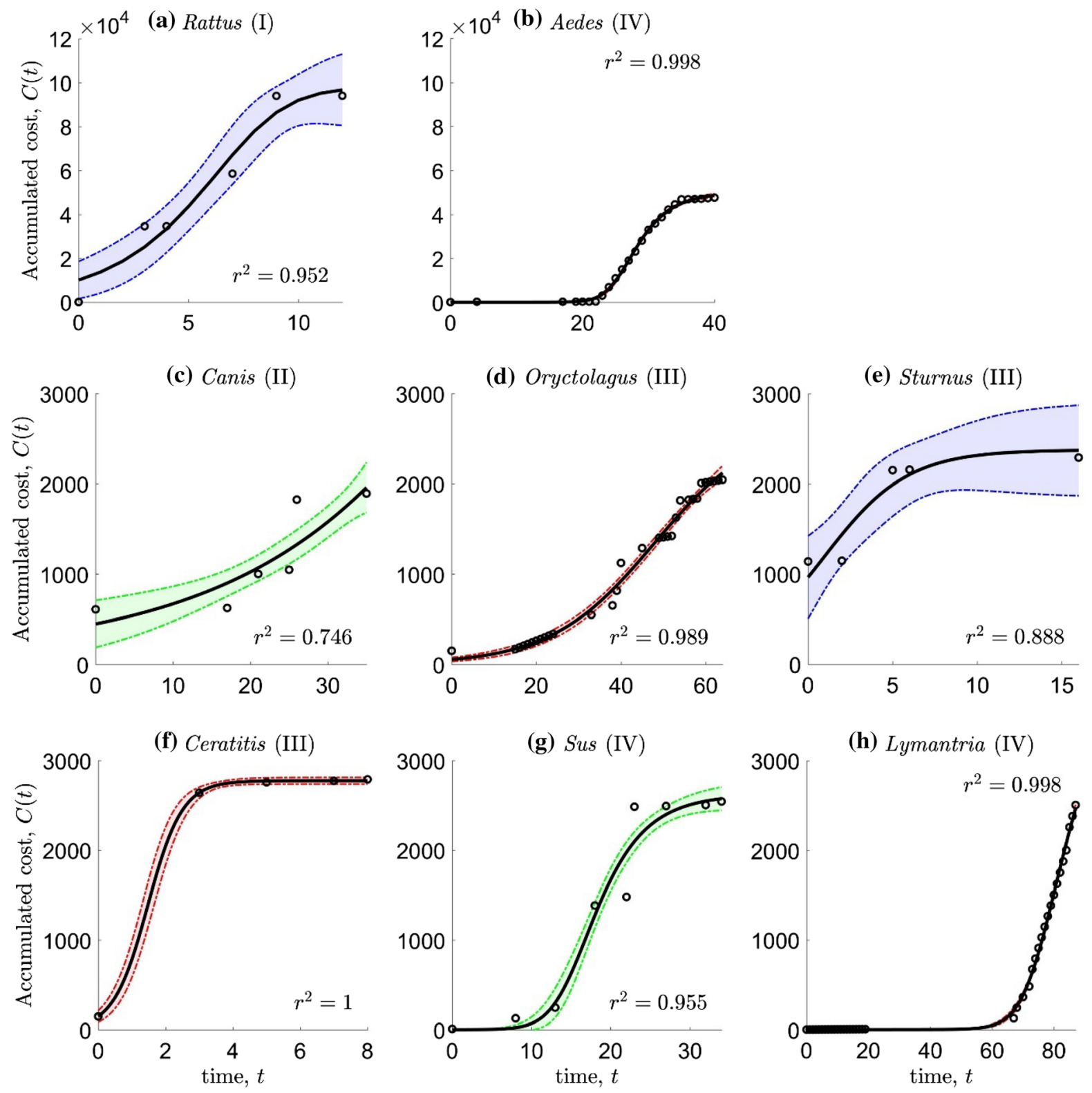

Fig. 4 Plot of the best fit accumulated cost model (either Types I-IV) against the cost data (US\$ million), with the reported $r^{2}$ value. The best fitted model for each is indicated in parentheses after the name of each genera; also see Table 2. The shaded areas represent confidence regions for the range of predicted

were used for those genera with higher data variability, and comparatively, a smaller number of reported costs (Tables 1, 3).

Rattus (Type I) costs were transitioning to the saturation phase, whilst Canis (Type II) costs were found to be accelerating. Nonetheless, within model cumulative costs with confidence levels $95 \%$ (red), $80 \%$ (blue) and 50\% (green) (see Table 3). See Appendix A5 for the corresponding plots for each genus with accumulated cost as a function of population density

types, curvatures differed substantially in their cost accumulation phases (see Fig. 4, and Appendices A4A5 for the corresponding population density-time and accumulated cost-density functions). Among the Type III model fits, we found Oryctolagus in the early phase with gradually increasing accumulated costs, Sturnus 
Table 2 The best fit accumulated cost model (either Types I-IV) quantified by the statistical metrics $\left(r^{2}\right)$ and $(R M S E)$. We also report the values of the maximum accumulated cost $\left(C_{\max }\right.$ in US\$ million)

\begin{tabular}{lllll}
\hline Genus & $\begin{array}{l}\text { Best fit } \\
\text { cost model }\end{array}$ & $\begin{array}{l}\text { Coefficient of } \\
\text { determination } r^{2}\end{array}$ & $\begin{array}{l}\text { Root mean square } \\
\text { error } R M S E\end{array}$ & $\begin{array}{l}\text { Maximum accumulated } \\
\text { cost } C_{\max }\end{array}$ \\
\hline (a) Rattus & I & 0.952 & 10,500 & 97,962 \\
(b) Aedes & IV & 0.998 & 858 & 49,759 \\
(c) Canis & II & 0.746 & 369 & 11,110 \\
(d) Oryctolagus & III & 0.989 & 79.4 & 2689 \\
(e) Sturnus & III & 0.888 & 275 & 2375 \\
(f) Ceratitis & III & 1 & 14.7 & 2774 \\
(g) Sus & IV & 0.955 & 269 & 2622 \\
(h) Lymantria & IV & 0.998 & 35.1 & 4075 \\
\hline
\end{tabular}

at the transition to reaching the stable plateau, and lastly Ceratitis already having reached the plateau phase. Interestingly, this illustrates that the same model type can reflect different stages of the population dynamics depending on the taxa considered (see Appendix A4). Similarly, for Type IV models, Lymantria exhibited cost cumulations in an early phase, with a steep increase in costs, whilst Aedes and Sus were more advanced.

Marked differences in the magnitude of costs were also exhibited within and between model types (Table 2), with Rattus exceeding all other genera, by far, in the total amount of damages incurred (i.e., greatest $C_{\max }$ ), followed by Aedes, with approximately half the Rattus total cost. In general, $C_{\max }$ was one order of magnitude higher for Rattus, Aedes and Canis when compared to the other taxa (Table 2). Accumulated maximum costs of Oryctolagus, Sturnus, Ceratitis and Sus were predicted to be similar in value, ranging in between US\$ 2375 and 2774 million (2007), whereas the maximum cost for Lymantria was slightly higher (US\$ 4075 million) (Table 2).

One advantage of the dynamical modelling process is that it can provide information regarding ecological parameters for taxa at a global scale directly from the cost data (i.e., a top-down approach). As a result, we can infer how the population density evolves with time (see Appendix A4). We note that our carrying capacity values should not be interpreted as the true maximum population density that the species can reach globally, but are reflective of a proportional maximum. While values of $K$ require rescaling by some unknown, potentially disparate constant across taxa in order to be interpretable, our fitted intrinsic growth rates can be compared directly among taxa if cost-density functions are constant through time. The highest intrinsic growth rate was found for Ceratitis, with a value $\alpha=$ 1.93 (Table 3), which explains the comparatively rapid cost accumulation with a quick progression towards the maximum cost (Fig. 4). This was followed by Sturnus, Rattus, Aedes and Sus, with a lower (but similar) value of $\alpha$ lying between 0.1 and 1 , representing slower growth. The remaining taxa exhibited a much lower intrinsic growth rate with $\alpha<0.1$, which was reflected by a greater lag or delayed increase in the cost accumulation (Fig. 4, Table 3). See Appendix A3 for a compiled list of ecological and model shape parameters as they appear in Eqs. (4) and (5).

\section{Discussion}

The present study developed and applied a novel mathematical model to examine and predict the cumulative damage costs of IAS over time. Among eight genera containing notorious invaders, we report marked differences in cost cumulations. Instances of high costs likely mirror the widespread distribution of genera which damage infrastructure, agriculture and represent threats for human health (Meerburg et al. 2009; Luis et al. 2013; Iwamura et al. 2020). Interestingly, the best fitting models, and their underlying parameters, differed among genera, indicating that the trajectories of cost cumulations can differ substantially among IAS; these differences can be explained by several factors, potentially including the 
Table 3 Confidence intervals for the ecological parameters $K$ and $\alpha$, where smaller confidence levels were used for those genera with high data variability and relatively smaller sample size. Confidence levels used are $95 \%$ (red), $80 \%$ (blue) and
$50 \%$ (green)—corresponding to the colour scheme in Fig. 4. Note that the lower interval limit for the carrying capacity for Canis was negative and thus cut off at zero

\begin{tabular}{|l|lllll|}
\hline Genus & $\begin{array}{l}\text { Confidence } \\
\text { level }\end{array}$ & $\begin{array}{l}\text { Carrying } \\
\text { capacity, } K \\
\text { (per unit area) }\end{array}$ & $\begin{array}{l}\text { Confidence } \\
\text { interval } \\
\text { for } K\end{array}$ & $\begin{array}{l}\text { Intrinsic } \\
\text { growth } \\
\text { rate, } \alpha \\
\text { (per year) }\end{array}$ & $\begin{array}{l}\text { Confidence } \\
\text { interval for } \alpha\end{array}$ \\
\hline (a) Rattus & $80 \%$ & 48.56 & {$[9.66,87.46]$} & 0.32 & {$[0.16,0.48]$} \\
\hline (b) Aedes & $95 \%$ & 228.59 & {$[105.81,351.38]$} & 0.27 & {$[0.25,0.29]$} \\
\hline (c) Canis & $50 \%$ & 5.06 & {$[0,18.9]$} & 0.02 & {$[0.02,0.03]$} \\
\hline (d) Oryctolagus & $95 \%$ & 42.91 & {$[29.47,56.36]$} & 0.08 & {$[0.07,0.09]$} \\
\hline (e) Sturnus & $80 \%$ & 2.29 & {$[1.24,3.35]$} & 0.40 & {$[0.03,0.77]$} \\
\hline (f) Ceratitis & $95 \%$ & 16.24 & {$[9.37,23.11]$} & 1.93 & {$[1.69,2.17]$} \\
\hline (g) Sus & $50 \%$ & 7.95 & {$[1.42,14.48]$} & 0.22 & {$[0.17,0.28]$} \\
\hline (h) Lymantria & $95 \%$ & 252.49 & {$[87.29,417.69]$} & 0.09 & {$[0.08,0.1]$} \\
\hline
\end{tabular}

sectors that the IAS impact, their abundance, distribution, ecology and their attention from researchers and other stakeholders that report damages. Furthermore, we determined differences in intrinsic growth rates of costs among genera due to changes in density, indicating differential lag time effects in the development of costs at the global scale. The exponential growth in costs shown by most taxa suggests that management actions could, reciprocally, result in exponential reductions of these costs below certain population thresholds. Whilst there are limitations to our approach, including considerations for future costs in novel invaded regions where species could still be far from $C_{\max }$ and $K$, and while underlying cost data are poorly available, these models help to elucidate how reported invasion costs have developed over time among taxa, informing management strategies for IAS. This potentially includes future IAS without a current invasion history within these focal genera, given high projected invasion rates in future (Seebens et al. 2021).

\section{Cost cumulation model}

The assessments were restricted to the calculation of the economic cost resulting from damages, which represent valuable indicators of the impact of biological invasions (US Congress 1993; Williamson 1998). Conversely, management costs may be more disparately reported, due to changeable investment priorities, research focuses and governmental policies. As such, the costs due to IAS projected here are underestimates, especially since we excluded uncertain damage cost types (i.e., predictions and low reliability costs), management costs, and additional filtering steps that omitted costs above or below the country-level scale, and notwithstanding additional gaps in underlying cost reporting.

It is important to note that the time of initial cost onset in our model is not the onset of each genus' invasion. Our cost curve typology is meant to describe only the shape of the accrual of detected damage costs over time, rather than that of the invasion trajectory from start to finish. In an analogous description of the shape of detected IAS spread trajectories; for example, Shigesada et al. (1995) defined their spread typology 
after accounting for a variable lag phase across species. In the same way, we model only the damage cost accumulation of IAS after the first report of their economic impacts. Prior to this detection, IAS can be subject to a variety of factors such as Allee effects, variable spread rates, and low cost detection effortespecially in the case of unintentional introductions or species with less of a nuisance status (Hastings et al. 2005), which cause variable lag times between the dates of first introduction of each genus in our dataset and their first cost detection (see Appendix A6). For instance, Aedes spp. have reported lag times of below 20 years (i.e., initial cost detections less than 20 years after their known date of first introduction) in their invaded countries, while Lymantria. spp were present for 90 years before their impacts were reported in Canada. This difference likely reflects the nuisance status of mosquitoes in terms of public health (Weber 1979), and the delay in spread and subsequent substantial forest impacts of Lymantria in North America (Aukema et al. 2011).

The assumption of logistic growth was justified by its explanatory power in the context of biological invasions (Lewis et al. 2016). In particular, it successfully models a common invasion scenario, where population expansion decreases as resources become scarce, and levels off when the carrying capacity of the environment is reached. Alternatives to this growth model exist, such as the more complicated forms: 'generalized logistic growth' (Tsoularis and Wallace 2002) or the 'Allee effect' (Dennis 2002; Boukal and Berec 2002; Courchamp et al. 2008). Also, in more complex scenarios, population dynamics can exhibit marked 'boom' and 'bust' dynamics, where the invader density can reach high levels, but then substantially decline to lower levels-which has been observed for a variety of species (Allmon and Sebens 1988; Creed and Sheldon 1995; Williamson and Fitter 1996; Zaitsev and Marnaev 1997). Lastly, other species have been observed to exhibit oscillatory behaviors (Ross and Tittensor 1986; Elkinton and Liebhold 1990). These more complex dynamics and associated alternative functional forms should be considered when the fit of a simpler model is poor, which was not the case in our study.

Our cost modelling approach accounts for the population dynamics of various genera, and thus provides a useful framework for investigating temporal cost patterns across various habitat types and taxonomic groups. By analyzing the shape of the costtime curves characterized by model Types (I)-(IV), we were able to capture how impacts accrue not only across taxa, but also at different stages of an invasion process. Further, our approach was fitted against actual damage cost data extracted from the most comprehensive database to date (InvaCost). These data are, however, subject to a series of limitations that likely lead to an underestimation of reported costs relative to true economic impacts of IAS (Diagne et al. 2020b). Accordingly, the Types of model selected here were inherently influenced by the nature of underlying data, suggesting that the resolution of cost reporting should be improved for economic damages globally. Yet, the consistent excellent fits across genera is an indication of a certain degree of robustness not only of the models but also of the cost data. More generally, studies on temporally dynamic models of species population growth are plentiful in the literature (Petrovskii and $\mathrm{Li}$ 2006; Kawasaki and Shigesada 2007; Hart and Avilés 2014; Lohr et al. 2017 etc.); however, very few rely on real cost data, and have instead focused more on a theoretical examination of optimal control (Yokomizo et al. 2009; Hastings et al. 2007; Baker et al. 2019).

Model Types and maximum accumulated costs

Cost cumulations differed substantially among the genera assessed in the present study, resulting in their representations over the four model Types. Nonetheless, whilst Types I and II were displayed solely by Rattus spp. and Canis spp., respectively, Types III and IV were more common ( $n=3$ taxa each). All types provided an excellent fit to the data $\left(r^{2} \geq 0.952\right)$, with the exception of Canis spp. (Type II) and Sturnus spp. (Type III) with still high $r^{2}$ values-indicating good fits (see Table 2). The relative commonness of Type III and IV curves suggests a lack of broadscale support for saturation between invader density and impact across all genera, as not all displayed an asymptote in cost dynamics. Reciprocally, this is highly useful for management, as effective actions that reduce invader abundances could result in an exponential decrease in damage costs from invasions. However, this is less relevant for species with lower maximum costs, where reductions in costs could be relatively small in magnitude. 
The highest accumulated cost was quantified from Rattus spp. (Table 2). This is not surprising as this genus was one of the earliest taxa recognized as an IAS, and has reached nowadays a widespread, worldwide distribution (CABI 2019). We also note that the costs would be much higher for Rattus spp. should we have included management costs. Because rat invasions are known to have an extreme detrimental effect on numerous native species (Atkinson 1985), particularly when introduced to oceanic islands (Shiels et al. 2014; Ruffino et al. 2015) — in some cases leading to rapid species extinctions (Bell 1978), they have been very extensively managed. In addition to these ecological impacts, these rodents host more than sixty zoonotic diseases, reducing crop yields and food reserves, and posing a serious threat to human health (Meerburg et al. 2009; Luis et al. 2013). The next highest accumulated cost was assigned to Aedes spp., which was approximately half of the cost incurred by Rattus spp. (Fig. 4, Table 2).

Invaders within the Aedes genus are some of the fastest-spreading worldwide, producing detrimental impacts to both resident species and ecosystems, and also represent some of the most prominent insect vectors of diseases (e.g., Zika, dengue, chikungunya, and yellow fever) (Juliano and Lounibos 2005). For these insects, the invasion front of the yellow fever mosquito A. aegypti is expected to increase significantly in the future (Iwamura et al. 2020), indicating that associated costs will heighten further with climate change. Similarly, the congeneric A. albopictus, which produces desiccation-tolerant and freeze-resistant eggs (Medlock et al. 2012; Cuthbert et al. 2020), is likely to continue to spread through pathways such as the used tire and ornamental plant trades in temperate regions, as has occurred in Europe (Medlock et al. 2012). Such invasive range increases are exacerbated by climate change, especially for ectothermic animals (Bellard et al. 2013). Overall, mosquito-borne diseases cause millions of human deaths per year, and therefore sustained control efforts and integrated management programs are of utmost importance to prevent disease outbreaks (Roiz et al. 2018)—with high global economic damages being driven predominantly through healthcare costs. Early preventative measures are the most efficient means for controlling invasive mosquito species (amongst other taxa) as compared with longer term control actions (Leung et al. 2002; Vazquez-Prokopec et al. 2010). Moreover, given our focus on damage costs, these IAS control efforts could reduce longer-term economic damages. Whilst our mathematical model suggested costs from Aedes are saturating, we stress that, empirically, costs from such taxa will probably continue to escalate as they invade new areas, as human populations grow, and as novel pathogens emerge. The third most costly genus comprised Canis spp., where economic damages accrued as a result of livestock mortality and human medical expenditures associated with feral dog bites (Pimentel et al. 2000).

In contrast, the cost impacts of the remaining genera were found to be one order of magnitude lower, with similar cost saturation levels (Table 2). This is primarily due to relatively lower direct damages to human assets, and the lack of association with disease spread. Nonetheless, these costs are only lower relative to the costliest species and remain unacceptably high in absolute value. In addition, these other genera are known to be highly ecologically damaging, yet such damages are more difficult to quantify in economic value than impacts to primary human sectors (e.g., agriculture) (but see Hanley and Roberts 2019). It is in fact likely that costs from these genera, as is also the case for several other taxa, are currently highly underestimated (Diagne et al. 2020b). This suggests that better cost reporting is required to more accurately discern the density-impact relationship of IAS, and that this will lead to higher costs than those reported here.

\section{Cost trajectories}

Data permitting, the mathematical model presented could equally be applied locally or nationally to deduce cost trajectories at finer scales, and to compare different populations of IAS. For instance, the model we developed was applied in a recent study (alongside other statistical approaches) to analyze global trends in costs of aquatic IAS (Cuthbert et al. 2021). In that vein, populations at an invasion front may exhibit an earlier stage of cost cumulation as compared with longstanding invader populations. Whilst Ceratitis spp. exhibited a relatively rapid intrinsic growth rate $(\alpha>1)$, other groups such as Rattus spp., Aedes spp., Sturnus spp. and Sus spp. had intermediate growth rates $(0.1<\alpha<1)$, whereas growth rates of genera such as Canis spp., Oryctolagus spp. and Lymantria spp. were much lower $(\alpha<0.1)$ (Table 3). These 
(a) Rattus

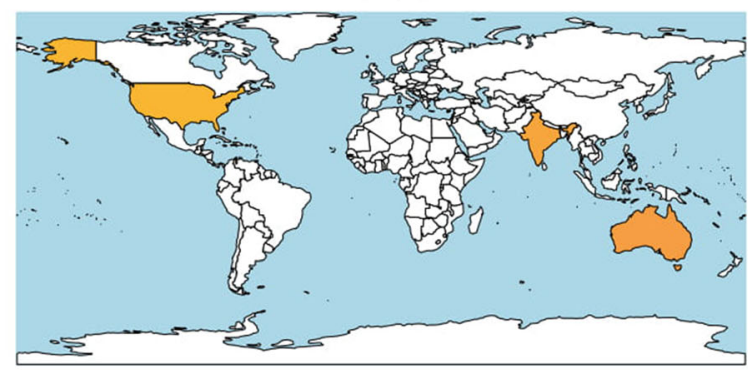

(c) Canis

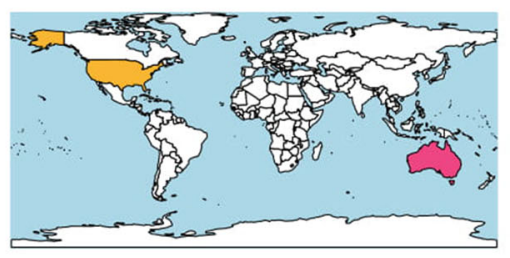

(f) Ceratitis

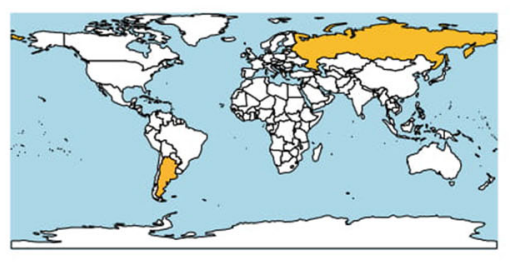

(d) Oryctolagus

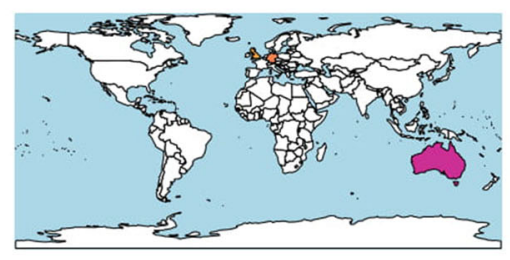

(g) Sus

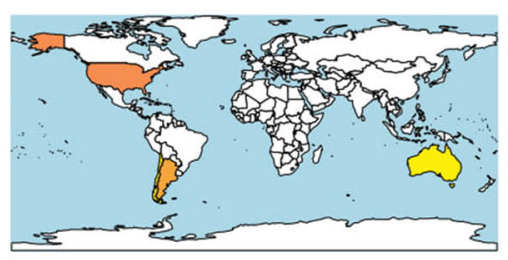

(b) Aedes

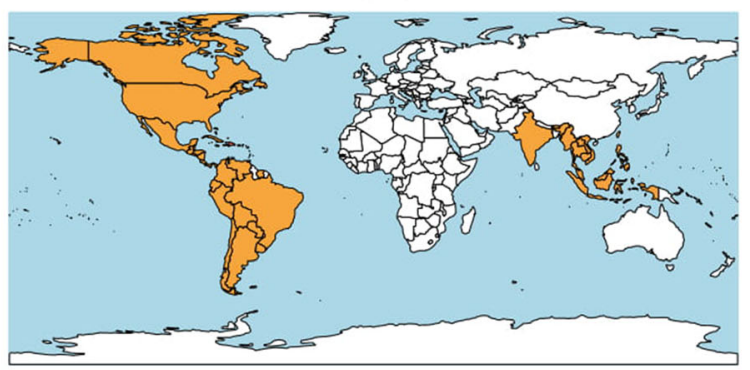

(e) Sturnus

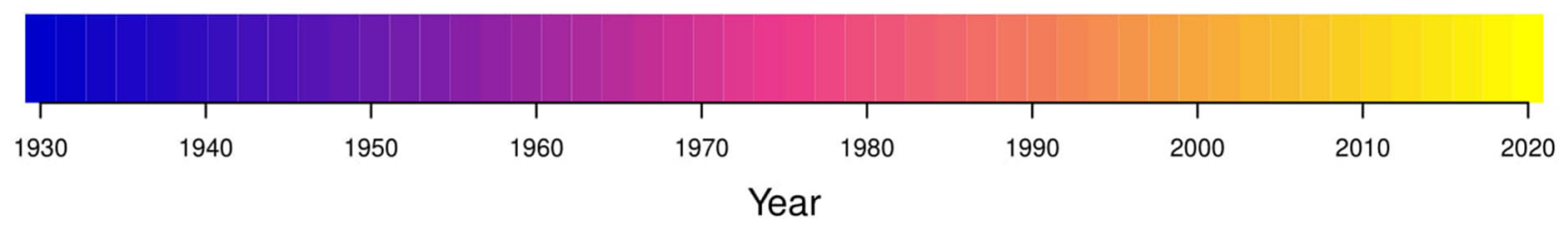

Fig. 5 Maps illustrating the global temporal distribution (years) in which the first cost was reported (independent of the magnitude of the respective cost) for each genus. The color ramp thus corresponds to the year in which the cost was first reported, regardless of its monetary value. Also see Appendix A2 for a total distribution of costs (US\$ million) at the country

patterns may also relate to the pathways associated with these species, as well as their life histories (e.g., rapid reproduction) or introduced ranges, with costs arising from new invaded areas through time (Fig. 5). For example, costs produced from invasions by Canis spp., and Oryctolagus spp. only occurred recently in the United States and Europe, and thus time lags in cost development likely emanate from delays in novel invasions, resulting in lower $\alpha$. level. These distributional data reflect the state of the Invacost database at the time of analysis. We note that entries used here may have since been updated in InvaCost v4.0 (for example, Lymantria spp. costs in Mexico are now listed as Potential rather than Observed)

The rapid intrinsic growth rate of Ceratitis spp. reflects a capacity to accrue substantial costs soon after establishment, with species within this genus known to cause substantial damages and losses to fruit crops, as well as through the transmission of fruit-rotting fungi (Cayol et al. 1994). For Aedes spp., the presence of dormant life stages that are well-adapted to succeed in urbanized environments through the exploitation of artificial habitats (i.e., artificial containers) mediates high invasion success (Medlock et al. 2012). This 
association with humans, coupled with short generation times and high fecundity, likely caused a relatively rapid increase in costs. Despite this, an intermediate growth rate in Aedes spp. may result from disparate cost reporting prior to the last two decades for those taxa, whereas taxa with a higher growth rate (i.e., Ceratitis spp.) were reported more recently, reducing delays in modelled population growth rates. Moreover, costs from disease are likely to accrue rapidly once a given pathogen or parasite is in circulation. Overall, the widespread pancontinental impacts of Aedes spp., and more particularly $A$. aegypti in tropical areas, may have led to a rapid increase in human health costs. This rapid increase could also be due to concurrent, analogous trends in urbanization, whereby this species has adapted to perform well in close association with humans. Similarly, Rattus spp. and Sturnus spp. can quickly reach high abundances in urban areas, where populations can spread disease and damage infrastructures, as well as agricultural enterprises elsewhere (Weber 1979; Linz et al. 2007; Meerburg et al. 2009).

In contrast, Lymantria spp. costs accrued more slowly, indicating that interest in this species was subject to a longer lag (Appendix A6), that its spread rates were slower, or that its impacts to its host trees took longer to become apparent following its invasion (invasion debt). Lymantria spp. exhibit just one generation per year (Doane and McManus 1981), with spread largely dependent on long-range assisted movements by humans (e.g., cars or boats) (Hajek and Tobin 2009). Our data indicate that the initial reported impacts from this species were relatively small, and increased rapidly only in the last few decades (but see our note in Methods about recent database corrections for this genus). However, rather than being an artefact associated with their life history, this could reflect growing interactions with growing urban forests within its invaded range (e.g., the United States, Twery 1991; Aukema et al. 2011). Indeed, Lymantria costs accrued only recently in the United States and Canada (Fig. 5). Similarly, Canis impacts have been slow to accrue, but that taxon has been characterized by more recent invasion cost reporting in North America. Moreover, despite high fecundity, invasions by Oryctolagus spp. occurred only relatively recently within Europe. In contrast, genera such as Aedes and Sus exhibited similar timing of cost reporting pancontinentally (Fig. 5). Finally, Ceratitis is characterized by very recent and concurrently reported invasion costs in Russia and Argentina.

Synthesis

Understanding the dynamics of cost development at different time scales, from initial cost accruals to large time saturation levels, is fundamentally required to better inform stakeholders and scientists of the IAS that require management actions. In this study, we presented a novel mathematical model which incorporates the dynamical nature of the species population, and demonstrated that it provides a useful framework for the analysis of cost accumulations. This model can identify genera whose damage costs may escalate rapidly - thus allowing data-informed prioritization and improved efficiency of control actions. In situations where costs have saturated relative to population density (such as Ceratitis and Sturnus), large population management expenditures may be necessary to impact cost trajectories. In contrast, exponential cost trajectories (such as for Lymantria and Oryctolagus) suggest that population management could result in exponential damage reductions. Although many mathematical models have been developed to relate ecological impacts and species abundances through 'density-impact' curves, very few have attempted to provide a direct link with the incurred costs, and backed them up with empirical cost data. While the costs of IAS are expected to increase in the forthcoming years, more IAS cost estimations are required in order to get improved assessments of temporal trends in costs of IAS, in turn ameliorating the predictive models and ultimately management strategies. Moreover, given cost-density relationships have been shown to exhibit intraspecific differences among populations (Strayer 2020), improved cost resolution at smaller scales could permit population level comparisons in cost developments.

Authors' contributions All authors conceptualized the study. $\mathrm{CD}$ and FC led the collection of data. DAA, EJH and CD analyzed and visualized the data. DAA developed the cost model and led the writing of the manuscript. RNC led the interpretation of the results. All authors contributed substantially to writing the manuscript and approved its submission. 
Funding DAA is funded by the Kuwait Foundation for the Advancement of Sciences (KFAS), grant no. PR1914SM-01 and the Gulf University for Science and Technology (GUST) internal seed fund, grant no. 187092. RNC acknowledges funding from the Alexander von Humboldt Foundation. CD is funded by the BiodivERsA-Belmont Forum Project "Alien Scenarios" (BMBF/PT DLR 01LC1807C). DR thanks InEECNRS for the support received for the network GdR 3647 CNRS 'Invasions Biologiques'.

Data availability Underlying data are publicly available in Diagne et al. (2020b-accessible at https://www.nature.com/ articles/s41597-020-00586-z) and in online repositories (https:// doi.org/10.6084/m9.figshare.12668570.v1; https://doi.org/10. $6084 / \mathrm{m} 9$. figshare.12928136). The final dataset used for analysis in this paper will be provided on the Dryad digital repository.

\section{Declarations}

Conflicts of interest The authors declare that there are no conflicting or competing interests.

Consent for publication All authors have seen and approved the manuscript and have consented for publication.

Open Access This article is licensed under a Creative Commons Attribution 4.0 International License, which permits use, sharing, adaptation, distribution and reproduction in any medium or format, as long as you give appropriate credit to the original author(s) and the source, provide a link to the Creative Commons licence, and indicate if changes were made. The images or other third party material in this article are included in the article's Creative Commons licence, unless indicated otherwise in a credit line to the material. If material is not included in the article's Creative Commons licence and your intended use is not permitted by statutory regulation or exceeds the permitted use, you will need to obtain permission directly from the copyright holder. To view a copy of this licence, visit http://creativecommons.org/licenses/by/4.0/.

\section{Appendix A1: Glossary of terms}

Categories used for each descriptive variable that corresponds to a specific column in the InvaCost database (Diagne et al. 2020b).

\begin{tabular}{ll}
\hline Column title & Description \\
\hline $\begin{array}{l}\text { Cost estimate per year } \\
\text { local currency }\end{array}$ & $\begin{array}{c}\text { The 'Raw cost estimate local } \\
\text { currency' transformed to a cost } \\
\text { estimate per year of the 'Period of } \\
\text { estimation' (obtained by dividing the } \\
\text { raw cost estimate by the number of } \\
\text { years* of the 'Period of estimation') }\end{array}$
\end{tabular}

\begin{tabular}{|c|c|}
\hline Column title & Description \\
\hline Impacted sector & $\begin{array}{l}\text { The sector impacted by the cost } \\
\text { estimate in our socio-ecosystems } \\
\text { (e.g., agriculture, health, public and } \\
\text { social welfare) }\end{array}$ \\
\hline Period of estimation & $\begin{array}{l}\text { If provided, the exact period of time } \\
\text { covered by the costs estimated, } \\
\text { otherwise the raw formulation (e.g., } \\
\text { late } 90 \text { 's, during } 5 \text { years) }\end{array}$ \\
\hline Probable starting year & The year range in which the cost is \\
\hline Probable ending year & $\begin{array}{l}\text { known or assumed to occur. When } \\
\text { not explicitly provided by the } \\
\text { authors, we mentioned 'unspecified' } \\
\text { in both columns unless the authors } \\
\text { provided a clear duration time. In } \\
\text { this case, we considered the } \\
\text { 'Publication year' as a reference for } \\
\text { the probable starting/ending year } \\
\text { from which we added/subtracted the } \\
\text { number of years* of the 'Period of } \\
\text { estimation'. In the case of a cost } \\
\text { estimate provided for a one-year } \\
\text { period straddling two calendar years, } \\
\text { we mentioned the latest year of the } \\
\text { cost occurrence in both columns. } \\
\text { When vague formulations were used } \\
\text { (e.g., early 90's), we still translated } \\
\text { them in probable ending/starting } \\
\text { year (e.g., 1990-1995). We will } \\
\text { harmonise the way these specific } \\
\text { cases are dealt with when reviewing } \\
\text { and validating new lines proposed by } \\
\text { new contributors }\end{array}$ \\
\hline Spatial scale & $\begin{array}{l}\text { The spatial scale considered for } \\
\text { estimating the cost: global } \\
\text { (worldwide-scale), intercontinental } \\
\text { (sites from two or more geographic } \\
\text { regions) continental ('geographic } \\
\text { region' level), regional (several } \\
\text { countries within a single geographic } \\
\text { region), country, site (for cost } \\
\text { evaluated at intra-country level, } \\
\text { including USA states) and unit (for } \\
\text { costs evaluated for a well-defined } \\
\text { surface area or entity) }\end{array}$ \\
\hline
\end{tabular}

*The number of years of the 'Period of estimation' is the difference between the 'Probable ending year' and the 'Probable starting year'. 
Appendix A2: Maps illustrating the distribution of total economic costs (US\$ million) at the country level.

These distributional data reflect the state of the Invacost database at the time of analysis. We note that one entry has since been updated in Invacost 4.0
(Lymantria spp. costs in Mexico are now listed as Potential rather than Observed) (a) Rattus

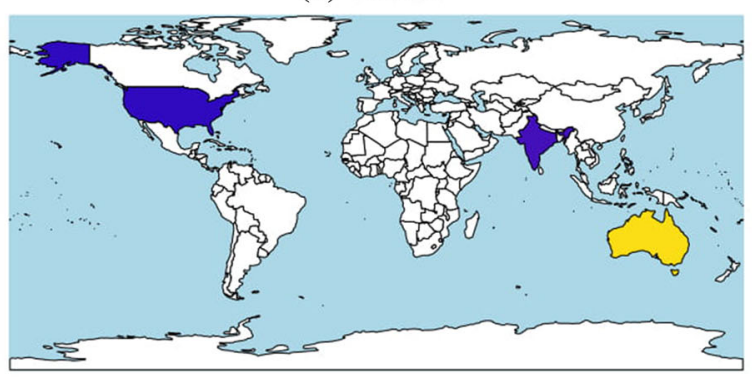

(b) Aedes

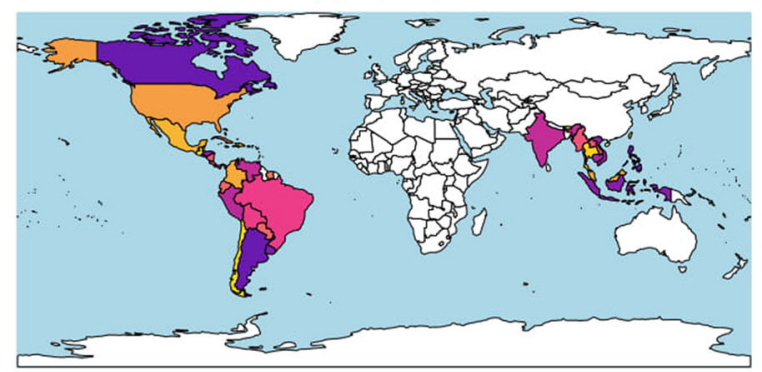

(e) Sturnus (c) Canis

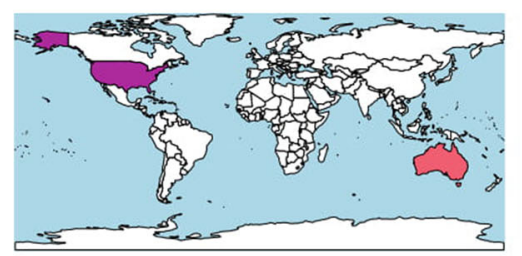

(f) Ceratitis

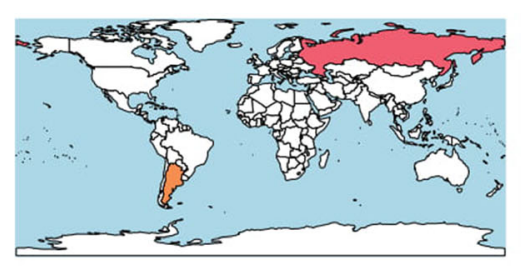

(d) Oryctolagus

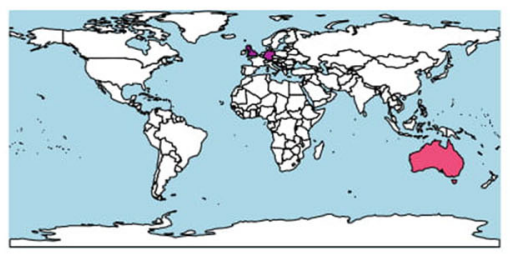

(g) Sus

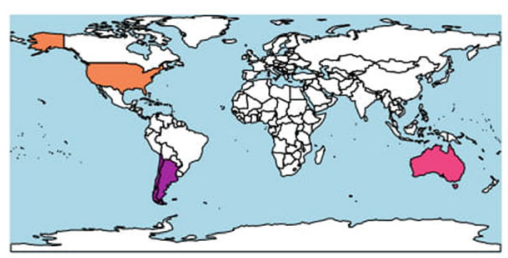

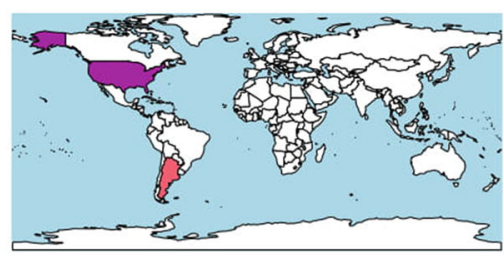

(h) Lymantria

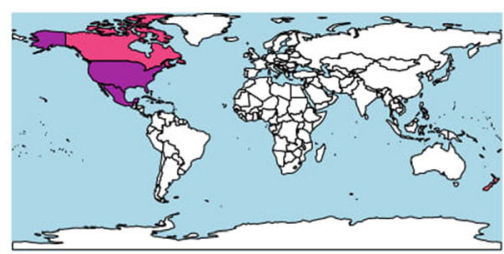

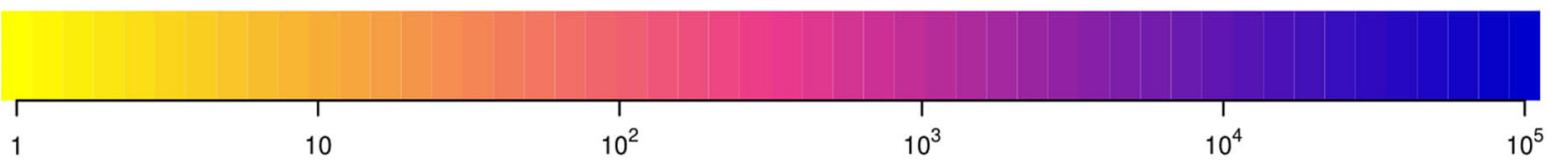

Cost (Million USD) 


\section{Appendix A3: Ecological and model shape parameters}

Parameter description: Maximum accumulated cost $C_{\max }$, Carrying capacity $K$ (per unit area), Intrinsic growth rate $\alpha$ (per year), Best fit cost model types (I-
IV, see Fig. 3), Model shape parameters $\left(s_{1}, s_{2}, s, A, B\right.$, as they appear in Eqs. (4) and (5)).

\begin{tabular}{lrrlllllll}
\hline Genus & \multicolumn{1}{c}{$\boldsymbol{C}_{\text {max }}$} & \multicolumn{1}{c}{$\boldsymbol{K}$} & $\boldsymbol{\alpha}$ & Best fit cost model type & $\boldsymbol{s}_{1}$ & $\boldsymbol{s}_{2}$ & $\boldsymbol{s}$ & $\boldsymbol{A}$ & $\boldsymbol{B}$ \\
\hline (a) Rattus & 97,962 & 48.56 & 0.32 & I & 0 & 0.1 & 10 & 2 & 0.5 \\
(b) Aedes & 49,759 & 228.59 & 0.27 & IV & 1 & 0.1 & 0 & 2 & 0 \\
(c) Canis & 11,110 & 5.06 & 0.02 & II & 0.5 & 0.1 & 5 & 1.0136 & 0.0067 \\
(d) Oryctolagus & 2689 & 42.91 & 0.08 & III & 1 & 1 & 0 & 4.3279 & 0.2689 \\
(e) Sturnus & 2375 & 2.29 & 0.40 & III & 1 & 1 & 0 & 4.3279 & 0.2689 \\
(f) Ceratitis & 2774 & 16.24 & 1.93 & III & 1 & 1 & 0 & 4.3279 & 0.2689 \\
(g) Sus & 2622 & 7.95 & 0.22 & IV & 1 & 0.1 & 0 & 2 & 0 \\
(h) Lymantria & 4075 & 252.49 & 0.09 & IV & 1 & 0.1 & 0 & 2 & 0 \\
\hline
\end{tabular}




\section{Appendix A4: Population density as a function of time}

The plots below show the population density for each genus as a function of time, given by Eq. (3) which is the solution of the logistic Eq. (2). This solution depends on the intrinsic growth rate $\alpha$ and carrying capacity $K$ with corresponding values given in
Appendix A3. The green marker represents the value of the initial density which is fixed as $u_{0}=u(0)=1$ for all genus. Note that the time-period is given in Table 1, where the initial year corresponds to time $t=0$, and measured in years thereafter.
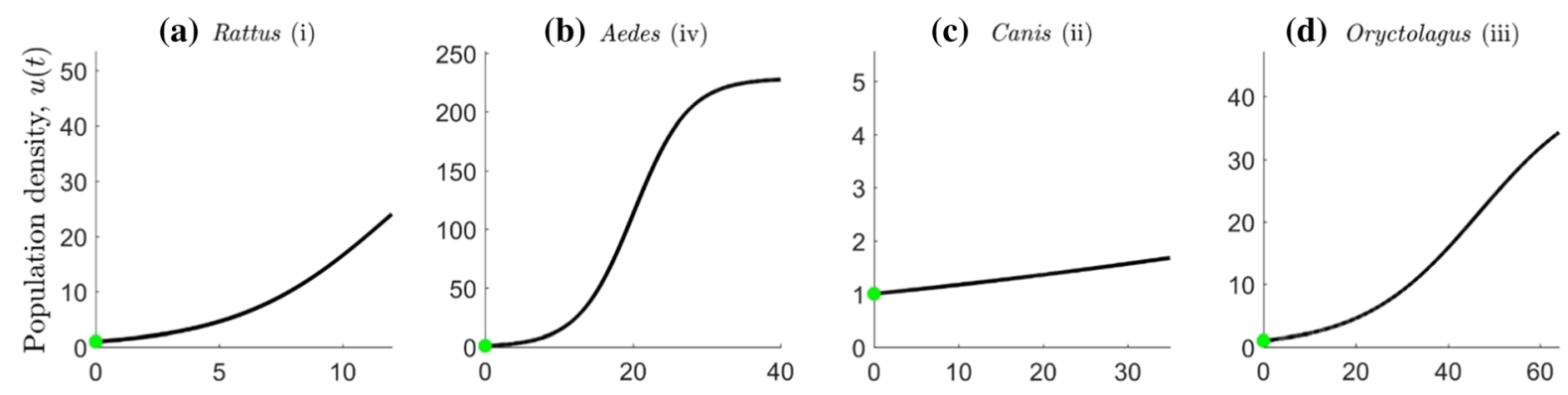

(e) Sturnus (iii)
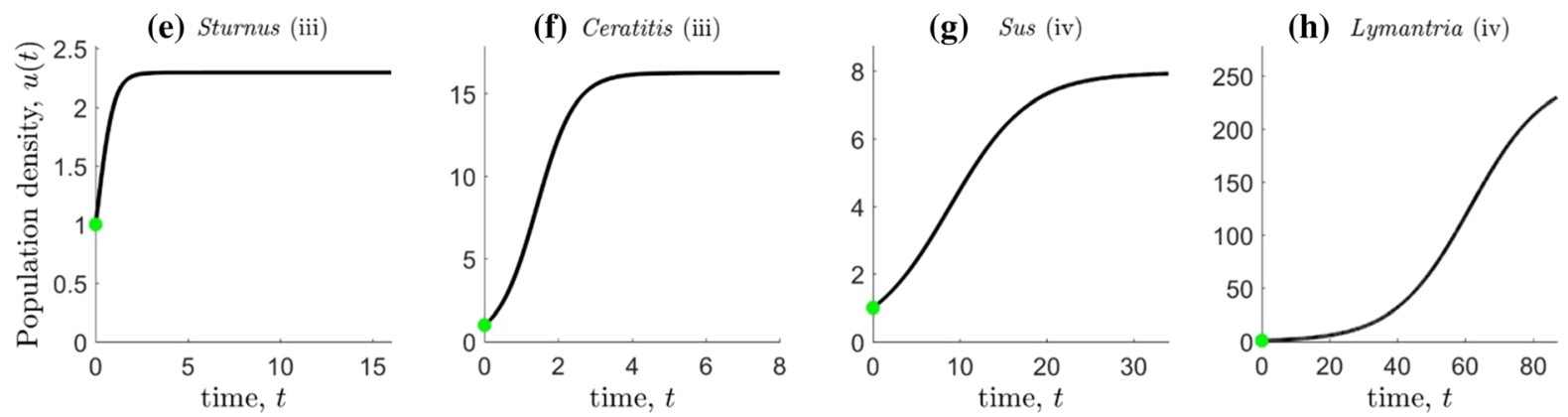


\section{Appendix A5: Accumulated costs as a function of population density}

The plots below show the accumulated cost-density functions for each genus. The best fitting model types (i)-(iv) are indicated, also see Fig. 2. The red marker represents the point where accumulated costs saturate at $C_{\max }$ precisely when the population density reaches the carrying capacity $K$. The corresponding ecological parameters, including model shape parameters are given in Appendix A3.
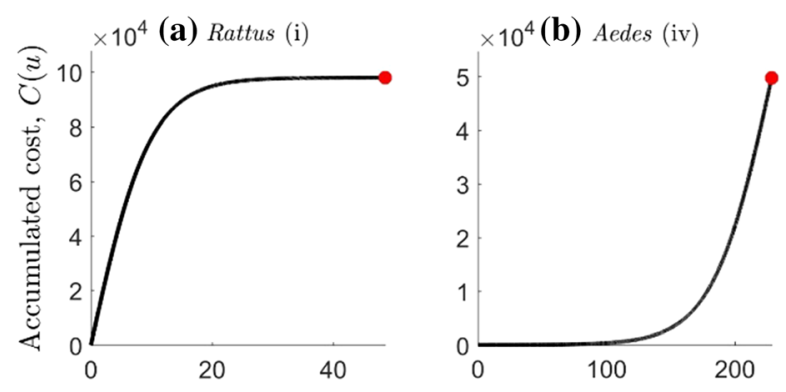

(c) Canis (ii)

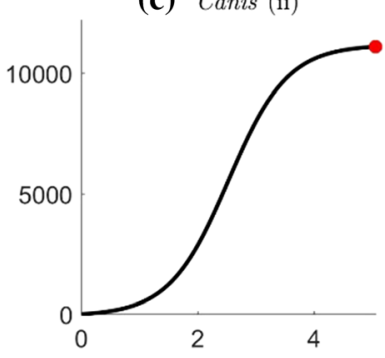

(d) Oryctolagus (iii)

(e) Sturnus (iii)
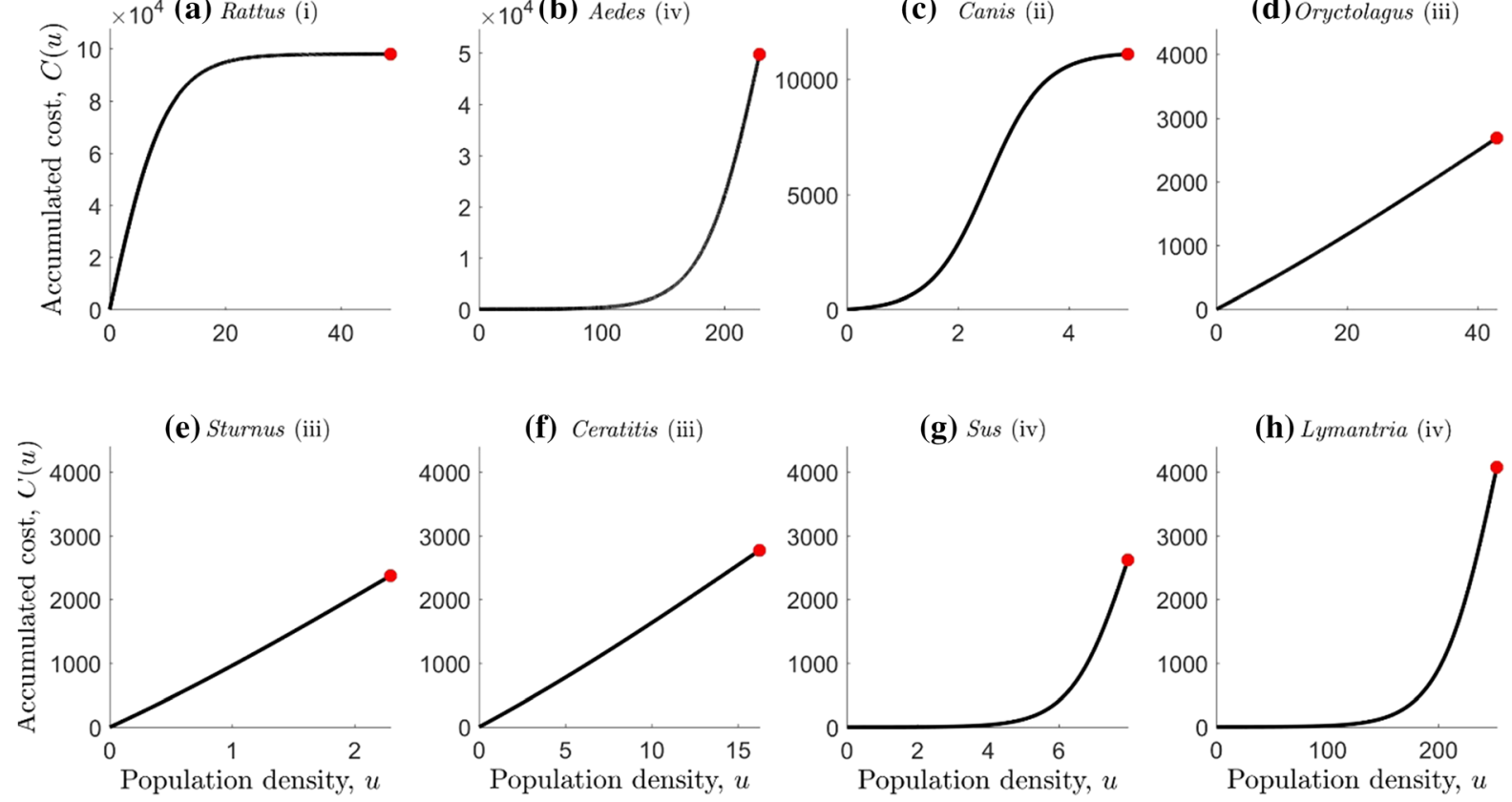

(h) Lymantria (iv)

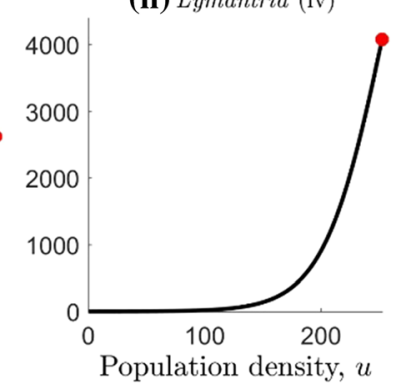




\section{Appendix A6: First cost record of each IAS genus in each invaded country, where known}

For reference, the year of first record in InvaCost is provided in order to determine the lag in cost detection following IAS introduction. Data on first records were obtained from the sTwist database, which is the most up-to-date global database for alien species' first records (Seebens et al. 2020).

\begin{tabular}{|c|c|c|c|c|}
\hline Genus & Country & $\begin{array}{l}\text { First } \\
\text { InvaCost } \\
\text { record }\end{array}$ & $\begin{array}{l}\text { First record } \\
\text { of invasion }\end{array}$ & $\begin{array}{l}\text { Lag } \\
\text { (years) }\end{array}$ \\
\hline Aedes & Brazil & 2000 & 1996 & 4 \\
\hline Aedes & Argentina & 2000 & 1980 & 20 \\
\hline Canis & USA & 1979 & 1930 & 49 \\
\hline Canis & Australia & 2000 & 1815 & 185 \\
\hline Lymantria & USA & 1933 & 1869 & 64 \\
\hline Lymantria & Canada & 2002 & 1912 & 90 \\
\hline Oryctolagus & $\begin{array}{l}\text { Great } \\
\text { Britain }\end{array}$ & 1955 & 1135 & 820 \\
\hline Oryctolagus & Australia & 1953 & 1788 & 165 \\
\hline Oryctolagus & Germany & 1970 & 1149 & 821 \\
\hline Oryctolagus & UK & 2001 & 1135 & 866 \\
\hline Rattus & Australia & 1998 & 1796 & 202 \\
\hline Rattus & UK & 2010 & 1751 & 259 \\
\hline Rattus & Denmark & 2002 & 1725 & 277 \\
\hline Rattus & USA & 2005 & 1703 & 302 \\
\hline Sturnus & Argentina & 2016 & 1987 & 29 \\
\hline Sturnus & Australia & 2002 & 1856 & 146 \\
\hline Sturnus & USA & 2000 & 1844 & 156 \\
\hline Sus & Argentina & 2017 & 1910 & 107 \\
\hline Sus & Australia & 1982 & 1788 & 194 \\
\hline Sus & Chile & 2016 & 1574 & 442 \\
\hline Sus & USA & 2000 & 1526 & 474 \\
\hline
\end{tabular}

\section{References}

Aikio S, Duncan RP, Hulme PE (2010) Lag-phases in alien plant invasions: separating the facts from the artefacts. Oikos 119:370-378

Allmon RA, Sebens KP (1988) Feeding biology and ecological impact of the introduced nudibranch, Tritonia plebeia, New England, USA. Mar Biol 99:375-385

Angulo E, Diagne C, Ballesteros-Meja L, Adamjy T, Ahmed DA et al (2020) Non-English languages enrich scientific knowledge: the example of economic costs of biological invasions. Sci Total Environ 775:144441
Aplin KP, Suzuki H, Chinen AA, Chesser RT, ten Have J et al (2011) Multiple geographic origins of commensalism and complex dispersal history of black rats. PLoS ONE 6(11):e26357

Aukema JE, Leung B, Kovacs K, Chivers C, Britton KO, Englin $\mathrm{J}$ et al (2011) Economic impacts of non-native forest insects in the continental United States. PLoS ONE 6(9):e24587

Atkinson IAE (1985) The spread of commensal species of Rattus to oceanic islands and their effect on island aviafaunas. In: Moors PJ (ed) Conservation of island birds, vol 3. ICBP Cambridge, Cambridge, pp 35-81

Baker CM, Diele F, Lacitignola D, Marangi C, Martiradonna A (2019) Optimal control of invasive species through a dynamical systems approach. Nonlinear Anal Real World Appl 49:45-70

Barnett SA (2001) The story of rats: their impact on us, and our impact on them. Allen \& Unwin, Crows Nest, NSW, Australia

Beggel S, Brandner J, Cerwenka AF, Geist J (2016) Synergistic impacts by an invasive amphipod and an invasive fish explain native gammarid extinction. BMC Ecol 16:32

Bell BD (1978) The big south cape island rat irruption. In: Dingwall PR, Atkinson IAE, Hay C (eds) The ecology and control of rodents in new zealand nature reserves. Information series, vol 4. Department of Land and Surveys, Wellington, pp 33-46

Bellard C, Thuiller W, Leroy B, Bakkeness M, Genovesi P et al (2013) Will climate change promote future invasions? Glob Change Biol 19:3740-3748

Bellard C, Cassey P, Blackburn TM (2016) Alien species as a driver of recent extinctions. Biol Lett 12:20150623

Blackburn TM, Pyšek P, Bacher S, Carlton JT, Duncan RP et al (2011) A proposed unified framework for biological invasions. Trends Ecol Evol 26:333-339

Blackburn T, Bellard C, Ricciardi A (2019) Alien versus native species as drivers of recent extinctions. Front Ecol Environ 17:203-207

Bogich TL, Liebhold AM, Shea K (2008) To sample or eradicate? a cost minimization model for monitoring and managing an invasive species. J Appl Ecol 45:1134-1142

Boukal D, Berec L (2002) Single-species models of the allee effect: extinction boundaries, sex ratios and mate encounters. J Theor Biol 218:375-394

Bradley BA, Laginhas BB, Whitlock R, Allen JM, Bates AE et al (2019) Disentangling the abundance-impact relationship for invasive species. Proc Natl Acad Sci 116:9919-9924

Bradshaw CJ, Leroy B, Bellard C, Roiz D, Albert C et al (2016) Massive yet grossly underestimated global costs of invasive insects. Nat Commun 7(1):1-8

Brown PR, Huth NI, Banks PB, Singleton GR (2007) Relationship between abundance of rodents and damage to agricultural crops. Agric Ecosyst Environ 120(2-4):405-415

Bucciarelli GM, Suh D, Lamb AD, Roberts D, Sharopton D et al (2018) Assessing effects of non-native crayfish on mosquito survival. Conserv Biol 33:122-131

CABI (2019) Rattus rattus (black rat). In: Invasive species compendium. CAB International, Wallingford. www.cabi. org/isc 
Cayol JP, Causse R, Louis C, Barthes J (1994) Medfly Ceratitis capitata Wiedemann (Dipt., Trypetidae) as a rot vector in laboratory conditions. J Appl Entomol 117:338-343

Courchamp F, Berek L, Gascoigne J (2008) Allee effects in ecology and conservation. Oxford University Press, Oxford

Coutts SR, Helmstedt KJ, Bennett JR (2017) Invasion lags: the stories we tell ourselves and our inability to infer process from pattern. Divers Distrib 24(2):244-251

Crane K, Coughlan NE, Cuthbert RN, Dick JTA, Kregting L et al (2020) Friends of mine: an invasive freshwater mussel facilitates growth of invasive macrophytes and mediates their competitive interactions. Freshw Biol 65:1063-1072

Creed RP, Sheldon SP (1995) Weevils and watermilfoil: did a North American herbivore cause the decline of an exotic plant? Ecol Appl 5:1113-1121

Crooks JA (2005) Lag times and exotic species: the ecology and management of biological invasions in slow-motion. Écoscience 12(3):316-329

Cuthbert RN, Cunningham EM, Crane K, Dick JTA, Callaghan A et al (2020) In for the kill: novel biosecurity approaches for invasive and medically important mosquito species. Manag Biol Invasions 11(1):9-25

Cuthbert RN, Pattison Z, Taylor NG, Verbrugge L, Diagne C et al (2021) Global economic costs of aquatic invasive alien species. Sci Total Environ 775:145238

Dennis B (2002) Allee effects in stochastic populations. Oikos 96(3):389-401

Diagne C, Catford JA, Essl F, Nuñez MA, Courchamp F (2020a) What are the economic costs of biological invasions? A complex topic requiring international and interdisciplinary expertise. NeoBiota 63:25-37

Diagne C, Leroy B, Gozlan RE, Vaissière AC, Assailly C et al (2020b) InvaCost, a public database of the economic costs of biological invasions worldwide. Sci Data 7:277

Dickey JWE, Cuthbert RN, South J, Britton JR, Caffrey J et al (2020) On the RIP: using the relative impact potential metric to assess the ecological impacts of invasive alien species. NeoBiota 55:27-60

Doane CC, McManus ML (1981) The gypsy moth: research towards integrated pest management. USDA forestry service technical bulletin No. 1585

Early R, Bradley B, Dukes J, Lawler J, Olden J et al (2016) Global threats from invasive alien species in the twentyfirst century and national response capacities. Nat Commun 7:1-9

Elgersma KJ, Ehrenfeld JG (2011) Linear and non-linear impacts of a non-native plant invasion on soil microbial community structure and function. Biol Invasions 13:757-768

Elkinton JS, Liebhold AM (1990) Population dynamics of gypsy moth in North America. Annu Rev Entomol 35:571-596

Elliott P, Aldridge DC, Moggridge GD, Chipps M (2005) The increasing effects of zebra mussels on water installations in England. Water Environ J 19(4):367-375

Epanchin-Niell RS (2017) Economics of invasive species policy and management. Biol Invasions 19:3333-3354

Essl F, Dullinger S, Rabitsch W, Hulme PE, Hulber K et al (2011) Socioeconomic legacy yields an invasion debt. Proc Natl Acad Sci USA 108:203-207
Finnoff DC, Shogren JF, Leung B, Lodge DM (2005) The importance of bioeconomic feedback in invasive species management. Ecol Econ 52:367-381

Hajek AE, Tobin PC (2009) North American eradications of asian and european gypsy moth. In: Hajek AE, Glare TR, O'Callaghan M (eds) Use of microbes for control and eradication of invasive arthropods. Progress in biological control, vol 6. Springer, Dordrecht

Hanley N, Roberts M (2019) The economic benefits of invasive species management. People Nat 1:124-137

Hart E, Avilés L (2014) Reconstructing local population dynamics in noisy metapopulations: the role of random catastrophes and Allee effects. PLoS ONE 9:e110049

Hastings A, Cuddington K, Davies KF, Dugaw CJ, Elmendorf S, Freestone A, Harrison S, Holland M, Lambrinos J, Malvadkar U, Melbourne BA (2005) The spatial spread of invasions: new developments in theory and evidence. Ecol Lett 8(1):91-101

Hastings A, Richard JH, Taylor CM (2007) A simple approach to optimal control of invasive species. Theor Popul Biol 70:431-435

Haubrock PJ, Turbelin AJ, Cuthbert RN, Novoa A, Taylor NG et al (2021) Economic costs of invasive alien species across Europe. NeoBiota, (in press)

Heikkilä J (2011) Economics of biosecurity across levels of decision-making: a review. Agron Sustain Dev 31(1):119-138

Hilton GM, Cuthbert RJ (2010) The catastrophic impact of invasive mammalian predators on birds of the UK Overseas Territories: a review and synthesis. Ibis 152(3):443-458

Iwamura T, Guzman-Holst A, Murray KA (2020) Accelerating invasion potential of disease vector Aedes aegypti under climate change. Nat Commun 11:2130

Jackson MC, Ruiz-Navarro A, Britton JR (2015) Population density modifies the ecological impacts of invasive species. Oikos 124:880-887

Jensen A (1975) Comparison of logistic equations for population growth. Biometrics 31(4):853-862

Juliano SA, Lounibos LP (2005) Ecology of invasive mosquitoes: effects on resident species and on human health. Ecol Lett 8(5):558-574

Kawasaki K, Shigesada N (2007) An integrodifference model for biological invasions in a periodically fragmented environment. Jpn J Ind Appl Math 24:3-15

Laverty C, Green KD, Dick JTA, Barrios-O’Neill D, Mensink PJ et al (2017) Assessing the ecological impacts of invasive species based on their functional responses and abundances. Biol Invasions 19:1653-1665

Lehmann P, Ammunét T, Barton M, Battisti A, Eigenbrode SD et al (2020) Complex responses of global insect pests to climate warming. Front Environ Ecol 18(3):141-150

Leroy B, Kramer AM, Vaissière AC, Courchamp F, Diagne C (2020). Analysing global economic costs of invasive alien species with the invacost $R$ package. bioRxiv 2020

Leung B, Lodge DM, Finnoff D, Shogren JF, Lewis MA et al (2002) An ounce of prevention or a pound of cure: bioeconomic risk analysis of invasive species. Proc R Soc London B 269(1508):2407-2413

Lewis M, Petrovskii SV, Potts J (2016) The mathematics behind biological invasions. Springer, New York 
Linz GM, Homan HJ, Gaukler SM, Penry LB, Bleier WJ (2007) European starlings: a review of an invasive species with far-reaching impacts. Managing vertebrate invasive species: proceedings of an international symposium. USDA/ APHIS/WS, National Wildlife Research Center, Fort Collins, CO

Lohr CA, Hone J, Bode M, Dickman CR, Wenger A et al (2017) Modeling dynamics of native and invasive species to guide prioritization of management actions. Ecosphere 8:e1822

Luis A, Hayman DT, O'Shea T, Cryan P, Gilbert AT et al (2013) A comparison of bats and rodents as reservoirs of zoonotic viruses: are bats special? Proc $\mathrm{R}$ Soc London B 280:20122753

Malcolm J, Markham A (2000) Global warming and terrestrial biodiversity decline. WWF, Washington, DC

Medlock JM, Hansford KM, Schaffner F, Versteirt V, Hendrickx $G$ et al (2012) A review of the invasive mosquitoes in Europe: ecology, public health risks, and control options. Vector-Borne Zoonot 12:435-447

Meerburg B, Singleton GR, Kijlstra A (2009) Rodent-borne diseases and their risks for public health. Crit Rev Microbiol 2009(35):221-270

Moroń D, Skórka P, Lenda M, Kajzer-Bonk J, Mielczarek L et al (2019) Linear and non-linear effects of goldenrod invasions on native pollinator and plant populations. Biol Invasions 21:947-960

Nava-Camberos U, Riley DG, Harris MK (2001) Density-yield relationships and economic injury levels for Belmisia argentifolia (Homoptera: Aleyrodidae) in cantaloupe in Texas. J Econ Entomol 94:180-189

Panetta F, Gooden B (2017) Managing for biodiversity: impact and action thresholds for invasive plants in natural ecosystems. NeoBiota 34:53-66

Parker I, Simberloff D, Lonsdale W, Goodell K, Wonham M (1999) Impact: toward a framework for understanding the ecological effects of invaders. Biol Invasions 1:3-19

Parsons K, Quiring D, Piene H, Moreau G (2005) Relationship between balsam fir sawfly density and defoliation in balsam fir. For Ecol Manag 205(1-3):325-331

Petrovskii SV, Li BL (2006) Exactly solvable models of biological invasion. Chapman Hall/CRC, Boca Raton, FL

Pimentel D, Lach L, Zuniga R, Morrison D (2000) Environmental and economic costs of nonindigenous species in the United States. Bioscience 50:53-65

Pimentel D, Zuniga R, Morrison S (2005) Update on the environmental and economic costs associated with alien invasive species in the united states. Ecol Econ 15:273-288

Roberts CP, Uden DR, Allen CR, Twidwell D (2018) Doublethink and scale mismatch polarize policies for an invasive tree. PLoS ONE 13(3):e0189733

Robertson PA, Mill A, Novoa A, Jeschke JM, Essl F et al (2020) A proposed unified framework to describe the management of biological invasions. Biol Invasions 22(9):2633-2645

Roiz D, Wilson AL, Scott TW, Fonseca DM, Jourdain F et al (2018) Integrated Aedes management for the control of Aedes-borne diseases. PLoS Negl Trop Dis 12(12):e0006845

Ross J, Tittensor AM (1986) The establishment and spread of Myxomatosis and its effect on rabbit populations. Philos Trans R Soc B 314:599-606
Ruffino L, Zarzoso-Lacoste D, Vidal E (2015) Assessment of invasive rodent impacts on island avifauna: methods, limitations and the way forward. Wildl Res 42:185-195

Rumlerová Z, Vilà M, Pergl J, Nentwig W, Pyšek P (2016) Scoring environmental and socioeconomic impacts of alien plants invasive in Europe. Biol Invasions 18:3697-3711

Schaffner U, Steinbach S, Sun Y, Skjøth CA, de Weger LA et al (2020) Biological weed control to relieve millions from Ambrosia allergies in Europe. Nat Commun 11:1745

Seebens H, Blackburn TM, Dyer EE, Genovesi P, Hulme PE et al (2017) No saturation in the accumulation of alien species worldwide. Nat Commun 8:14435

Seebens H, Blackburn TM, Dyer EE, Genovesi P, Hulme PE et al (2018) Global rise in emerging alien species results from increased accessibility of new source pools. PNAS 115:E2264-E2273

Seebens H, Clarke DA, Groom Q, Wilson JRU, García-Berthou E, Kühn I, Roigé M, Pagad S, Essl F, Vicente J, Winter M, McGeoch M (2020) A workflow for standardising and integrating alien species distribution data. NeoBiota 59:39-59

Seebens H, Bacher S, Blackburn TM, Capinha C, Dawson W et al (2021) Projecting the continental accumulation of alien species through to 2050. Global Change Biol 27(5):970-982

Shiels AB, Pitt WC, Sugihara RT, Witmer GW (2014) Biology and impacts of Pacific island invasive species. 11. Rattus rattus, the black rat (Rodentia:Muridae). Pac Sci 68(2): $145-184$

Shigesada N, Kawasaki K (1997) Biological Invasions: theory and practice. Oxford Univ. Press, Oxford

Shigesada N, Kawasaki K, Takeda Y (1995) Modeling stratified diffusion in biological invasions. Am Nat 146(2):229-251

Simberloff D, Martin J, Genovesi P, Maris V, Wardle DA et al (2013) Impacts of biological invasions: what's what and the way forward. Trends Ecol Evol 28:58-66

Sofaer HR, Jarnevich CS, Pearse IS (2018) The relationship between invader abundance and impact. Ecosphere 9:e02415

Stigall A (2010) Invasive species and biodiversity crises: testing the link in the late devonian. PLoS ONE 5:e15584

Stockhoff BA (1993) Ontogenic change in dietary selection for protein and lipid by gypsy-moth larvae. J Insect Physiol 39:677-686

Strayer DL (2020) Non-native species have multiple abundance-impact curves. Ecol Evol 10(13):6833-6843

Tsoularis A, Wallace J (2002) Analysis of logistic growth models. Math Biosci 179:21-55 (PMID: 12047920)

Twery MJ (1991) Effects of defoliation by gypsy moth. In: Gottschalk KW, Twery MJ, Smith SI (eds) Proceedings, usda interagency gypsy moth research review, 1990. GTRNE-146. Radnor, PA: USDA Forest Service, Northeastern Forest Experiment Station. p. 152

US Congress, Office of Technology Assessment (1993) Harmful non-indigenous species in the United States. Washington, DC

Vanbergen AJ, Espíndola A, Aizen MA (2018) Risks to pollinators and pollination from invasive alien species. Nat Ecol Evol 2:16-25

Vander Zanden MJ, Hansen GJ, Latzka AW (2017) A framework for evaluating heterogeneity and landscape-level 
impacts of non-native aquatic species. Ecosystems 20:477-491

Vazquez-Prokopec GM, Chaves LF, Ritchie SA, Davis J, Kitron U (2010) Unforeseen costs of cutting mosquito surveillance budgets. PLoS Negl Trop Dis 4(10):e858

Veitch CR, Clout MN (2002) Turning the tide: the eradication of invasive species. IUCN Species Specialist Group, Gland, Switzerland and Cambridge UK

Walsh JR, Carpenter SR, Zanden MJV (2016) Invasive species triggers a massive loss of ecosystem services through a trophic cascade. Proc Nat Acad Sci 113:4081-4085

Weber WJ (1979) Health hazards from pigeons, starlings and English sparrows. Thomson Publications, California

Williamson M (1998) Measuring the impact of plant invaders in Britain. In: Starfinger U, Edwards K, Kowarik I, Williamson M (eds) Plant invasions: ecological consequences and human responses. Backhuys, Leiden, The Netherlands, pp 57-68
Williamson MH, Fitter A (1996) The characters of successful invaders. Biol Cons 78:163-170

Yokomizo H, Possingham H, Thomas M, Buckley Y (2009) Managing the impact of invasive species: the value of knowing the density - impact curve. Ecol Appl 19(2):376-386

Zaitsev Y, Marnaev V (1997) Biological diversity in the Black Sea: a study of change and decline. United Nations Publications, New York

Zenni RD, da Cunha WL, Musso C, de Souza JV, Nardoto GB et al (2020) Synergistic impacts of co-occurring invasive grasses cause persistent effects in the soil-plant system after selective removal. Funct Ecol 34:1102-1112

Publisher's Note Springer Nature remains neutral with regard to jurisdictional claims in published maps and institutional affiliations. 